\title{
Should patients prescribed long-term low-dose aspirin receive proton pump inhibitors? A systematic review and meta-analysis
}

\author{
A. Tran-Duy, ${ }^{1,2}$ F. H. Vanmolkot, ${ }^{3}$ M. A. Joore, ${ }^{1}$ A. W. Hoes, ${ }^{2}$ C. D. A. Stehouwer ${ }^{3,4}$
}

'Department of Clinical Epidemiology and Medical Technology Assessment, Maastricht University Medical Center, Maastricht, The Netherlands

${ }^{2}$ Julius Center for Health Sciences and Primary Care, University Medical Center Utrecht, Utrecht, The

Netherlands

${ }^{3}$ Department of Internal

Medicine, Maastricht University Medical Center, Maastricht, The

Netherlands

${ }^{4}$ CARIM School for

Cardiovascular Diseases,

Maastricht UMC+, Maastricht,

the Netherlands

Correspondence to: An Tran-Duy, Department of Clinical Epidemiology and Medical Technology Assessment, Maastricht University Medical Center, P.O. Box 5800, Maastricht 6202 AZ,

The Netherlands

Tel.: + 31433877536

Fax: +31433874419

Email: an.tranduy@mumc.nl.

\section{Disclosures}

None of the authors has conflict of interest with regard to finance, activities, relationships or affiliations

\section{SUMMARY}

Background: Several clinical guidelines recommend the use of proton pump inhibitors (PPIs) in patients taking low-dose aspirin but report no or limited supporting data. We conducted a systematic review and meta-analysis to examine the effects of co-administration of PPIs in patients taking low-dose aspirin on the risks of adverse gastrointestinal (GI) and cardiovascular (CV) events, and on patient adherence to aspirin. Methods: We searched PUBMED, EMBASE and Cochrane Central Register of Controlled Trials databases for relevant articles published through November 2013. We included randomised controlled trials (RCTs) and observational studies in patients taking low-dose aspirin with and without PPIs. Risk of bias was assessed using the Cochrane Collaboration's tool (for RCTs) and the Newcastle-Ottawa Scale (for observational studies). Pooled risk ratios (RRs) were computed using a random-effects model. Results: We included 13 studies, of which 12 (2 RCTs and 10 observational studies) reported on GI events, and one (cohort study) on both GI bleeding and CV events. No study reported on adherence to aspirin. Co-administration of PPIs in patients receiving low-dose aspirin was associated with risk reductions of $73 \%$ (RR $0.27,95 \% \mathrm{Cl} 0.17-0.42$ ) and $50 \%$ (RR $0.50,95 \% \mathrm{Cl} 0.32-0.80$ ) in the occurrence of peptic ulcer and Gl bleeding respectively. There was evidence of bias in publications reporting on the $\mathrm{Gl}$ events. Conclusions: The practice of co-prescribing PPIs in patients taking lowdose aspirin is supported by some data, but the evidence is rather weak. It currently remains unclear whether the benefits of co-administration of PPIs in users of low-dose aspirin outweigh their potential harms.

\section{Introduction}

Proton pump inhibitors (PPIs) are widely used for prevention and treatment of peptic ulcer disease. Recently, concerns have been expressed about the worldwide overprescription of PPIs in both primary and secondary care $(1,2)$, suggesting a lack of evidence that the benefits outweigh the harms of PPIs.

Patients receiving low-dose aspirin (30-325 mg/ day) constitute by far the largest proportion of the population taking antiplatelet drugs to prevent adverse cardiovascular (CV) events. These patients are at risk of peptic ulcer and ulcer complications (3-7), and for that reason are frequently prescribed PPIs. Although several guidelines recommend PPI use in patients receiving low-dose aspirin (8-12), no or limited supporting data are reported (Table 1 ).
These guidelines generally recommend PPIs in patients at a very high risk of gastrointestinal (GI) bleeding (e.g. a history of peptic ulcer), but are less clear regarding patients at lower risk. On the other hand, no recommendation regarding the use of PPIs in chronic aspirin users is made in other influential guidelines for prevention and management of $\mathrm{CV}$ diseases, such as the American Heart Association (AHA) (20-23), European Society of Cardiology (24), Joint British Societies (25) and World Health Organisation guidelines (26).

The argument for prescribing PPIs to prevent GI injury relates to the suppressive effect of these drugs on gastric acid secretion. However, acid does not seem to be an obligatory factor leading to GI injury since aspirin-induced ulcers can develop in an achlorhydric environment (27). Aspirin can accumulate 


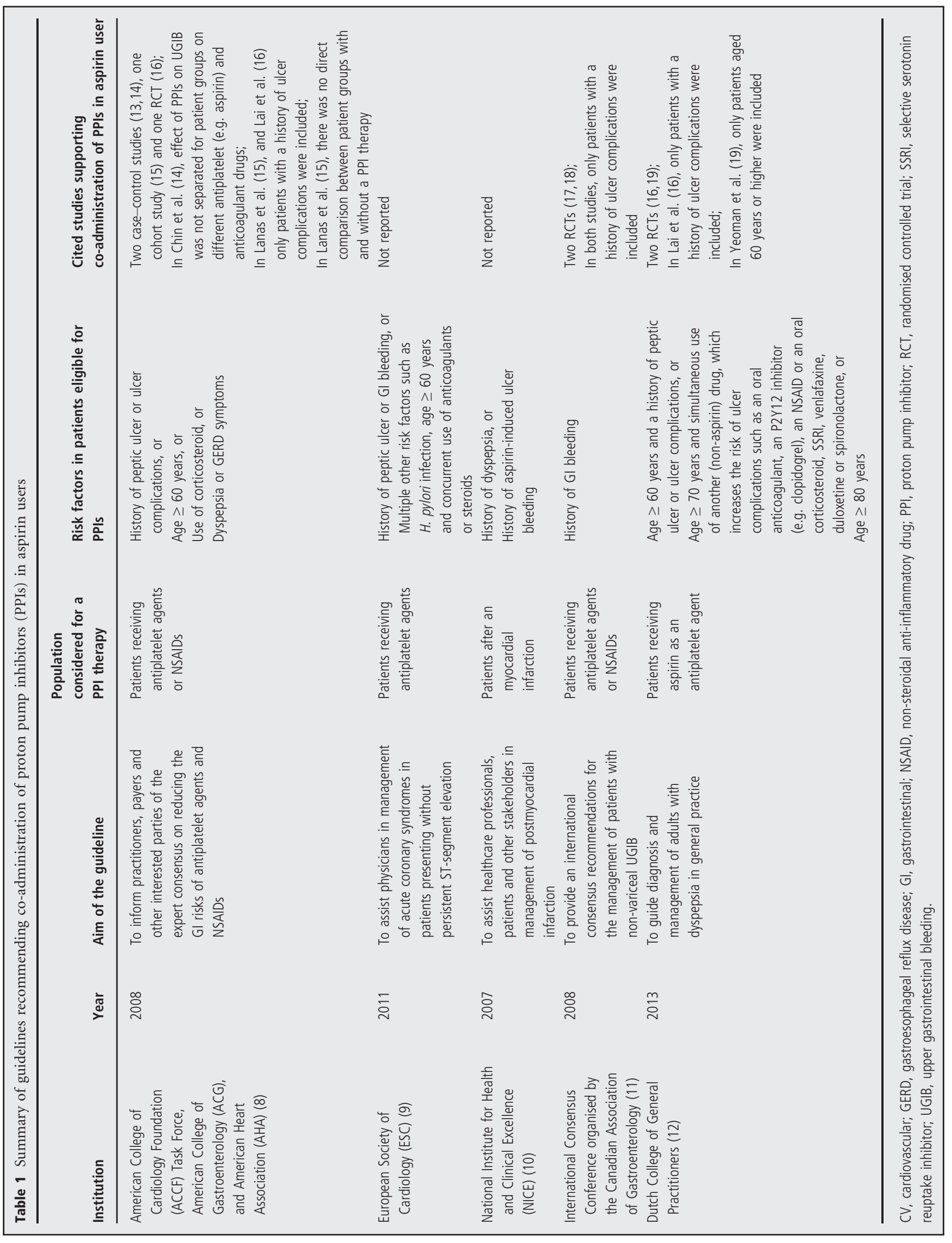


within epithelial cells of the stomach and duodenum and subsequently cause lysis (28). Also, aspirin impairs GI defence mechanisms, making epithelial cells more susceptible to topical attack by endogenous factors like acid and pepsin $(29,30)$. Suppressing acid secretion is, therefore, unlikely to completely prevent adverse GI events in patients receiving aspirin. This raises the question to what extent PPIs reduces the risk of adverse GI events. In addition, co-administration of PPIs may affect the CV preventive effects of low-dose aspirin in several ways; on the one hand, increased adherence to low-dose aspirin because of improved tolerability may enhance CV risk reduction; on the other hand, a PPI-induced reduction in the bioavailability of aspirin (31-33) may diminish the CV preventive effect of aspirin. So far, the overall risk-benefit ratio of co-administration of PPIs in patients receiving low-dose aspirin has not been established.

We performed a systematic review to determine whether, in patients on long-term low-dose aspirin and without a history of peptic ulcer or ulcer complications, co-administration of PPIs (i) reduces the risk of adverse GI events, (ii) modifies the risk of adverse CV events and (iii) increases adherence to aspirin prescriptions.

\section{Methods}

\section{Data sources and search strategy}

We searched PUBMED, EMBASE and Cochrane Central Register of Controlled Trials in November 2013 to identify all English-language studies on cotherapy with PPIs in patients receiving long-term aspirin for prevention of CV events. We used the search terms 'acetylsalicylic acid', 'aspirin', 'proton pump inhibitor', 'omeprazole', 'esomeprazole', 'pantoprazole', 'lansoprazole', 'dexlansoprazole', 'rabeprazole', 'gastric', 'duodenal', 'peptic', 'gastroduodenal', 'gastrointestinal', 'ulcer', 'injury', 'damage', 'bleeding', 'h(a) emorrhage', 'obstruction', 'perforation', 'toxicity', 'symptom', 'complication', 'cardiac', 'cardiovascular', 'coronary', 'carotid', 'artery', 'atherosclerotic', 'diabetes', 'event', 'risk', 'diseases', 'heart attack', 'myocardial infarction', 'stroke', 'death', 'mortality', 'survival', 'compliance' and 'adherence'. Detailed search queries are provided in Appendix A. We also manually scanned the bibliographies of relevant articles for additional studies.

\section{Eligibility criteria}

We included randomised controlled trials (RCTs) and observational studies (i.e. cohort or case-control studies) published through November 2013 that met the following criteria: (i) participants were receiving low-dose aspirin, defined as 75-325 mg daily, for CV prevention, and (ii) studies reported on any of the following outcomes: peptic ulcer, GI bleeding, gastric-outlet obstruction, gastric perforation, myocardial infarction, ischaemic stroke or CV death and adherence to aspirin.

For RCTs, we included studies that compared PPIs with placebo. For the observational studies, we included studies that assessed the association of concomitant use of aspirin and any PPIs, against the use of aspirin alone, with any of the above-mentioned outcomes. We excluded studies in which participants (i) were concomitantly receiving clopidogrel or any non-steroidal anti-inflammatory drug other than aspirin and (ii) had a history of peptic ulcer or ulcer complications.

\section{Study selection and data extraction}

The studies were reviewed in two stages by two independent reviewers (ATD and FHV). In the first stage, the titles and abstracts of all retrieved articles were screened to assess whether the studies met the inclusion criteria and did not meet the exclusion criteria. Where there was any uncertainty about the inclusion of a study, this issue was discussed between the two reviewers. Disagreements were referred to a third reviewer (CDAS or AWH) to achieve a resolution. In the second stage, full text of the potentially relevant studies were retrieved and reviewed using the same methods for selection and disagreement resolution as in the first stage. The following information was independently extracted from the included studies and jointly verified for accuracy: first author's surname, year of publication, country of study, study design, number of participants, duration of drug exposure, relevant outcomes, outcome definitions and characteristics of participants. We contacted authors when there was unclear information.

We assessed the methodological quality of the observational studies using the Newcastle-Ottawa Scale (NOS; ranging 0-9) (34) as recommended by the Cochrane Handbook for Systematic Reviews of Interventions (35). On this scale, a study is judged by giving points (stars in the NOS terminology) to items belonging to three categories: selection of the study groups, the comparability of the groups and the ascertainment of the exposure (for case-control studies) or outcome of interest (for cohort studies) (see Appendix B for details). To assess the risk of bias in RCTs, we used the Cochrane Collaboration's tool, which addresses the following domains: sequence generation, concealment of allocation sequence, blinding, incomplete outcome data, selective outcome reporting and any other problems that could put the studies at risk of bias. 


\section{Data synthesis and analysis}

Risk or rate ratios (RRs) with a 95\% confidence interval (CI) were calculated to quantify treatment effects. In case-control studies, odds ratios (ORs) were assumed to provide valid estimates of RRs (36). In cohort studies, we used the reported RRs adjusted for potential confounders whenever available. If RRs were not reported, we computed them by using raw data (if available) or by converting the reported ORs to RRs according to the Cochrane Handbook for Systematic Reviews of Interventions: $R R=\mathrm{OR} /$ $[1-\mathrm{ACR} \times(1-\mathrm{OR})]$, where ACR is assumed control risk (the rate of the event in the control group) (35). Hazard ratios were accepted as RRs. Pooled RRs were computed using a random-effects model.

The heterogeneity across studies was tested by the Q-statistic and quantified by the total inconsistency in the study results $\left(I^{2}\right)$ and the between-study variance $\left(\tau^{2}\right)(37,38)$. Subgroup analysis was also performed to assess the potential impact of quality of observational studies (NOS $\geq 5$ vs. NOS $<5$ ), duration of PPI exposure ( $\geq 2$ months and $>7$ days) and study design (RCTs vs. observational studies) on the effect estimates. In a sensitivity analysis, the influence of individual studies on the summary statistics was examined by omitting one study at a time from the meta-analysis. Publication bias was assessed using funnel plots and Egger's regression test of funnel plot asymmetry (39).

All statistical analyses were performed using the $\mathrm{R}$ package metaphor (40). A p-value $<0.05$ was considered statistically significant.

\section{Results}

Figure 1 shows the flow chart of the selection of studies. The search identified 347 studies. After screening the titles, abstracts and full text, 13 studies were considered eligible for complete data extraction. Of these, four cohort studies (41-44) reported on the effect on peptic ulcer, five studies [two cohort $(45,46)$ and three case-control studies $(13,47,48)$ ] on GI bleeding, three studies [two RCTs $(19,49)$ and one cohort study $(50)]$ on both GI bleeding and peptic ulcer, and one cohort study (51) on both GI bleeding and CV events. Among nine studies that reported on GI bleeding, six studies indicated the outcomes as upper GI bleeding (UGIB) while the others did not specify the location of the bleeding. We found no studies investigating the effect of PPIs on adherence to aspirin. Table 2 shows the main characteristics of the included studies and Table 3 shows outcomes, characteristics of the drug treatments and study quality (for detailed quality assessment of the observational studies, see Appendix B).

\section{Impact of PPIs on peptic ulcer}

\section{Pooled effect}

Two RCTs and five cohort studies reported on the effect on peptic ulcer. Only two $(43,44)$ of the five cohort studies adjusted the effect estimates for potential confounding. A total number of 5407 patients (2608 patients on PPIs) were included in the analysis. The directions of the estimated RRs and their 95\% CIs were consistently in favour of PPI use in all studies. When all the estimates were pooled, concomitant use of PPIs was associated with a $73 \%$ risk reduction compared with no PPI therapy (pooled $\mathrm{RR}=0.27 ; \quad 95 \% \quad \mathrm{CI}=0.17-0.42 ; \quad \mathrm{p}<0.001 ; \quad$ Figure 2A). Significant heterogeneity was present across studies $\left(\mathrm{p}=0.0013 ; I^{2}=63.8 \% ; \tau^{2}=0.20\right)$.

\section{Subgroup analysis}

The pooled RR (95\% CI) of the estimates from the two RCTs was $0.21(0.13-0.34)$; no significant heterogeneity between these RCTs was detected ( $p=0.26$; $\left.I^{2}=21.3 \% ; \tau^{2}=0.03\right)$. In contrast, significant heterogeneity was present across the five cohort studies ( $\left.\mathrm{p}=0.03 ; \quad I^{2}=58.6 \% ; \quad \tau^{2}=0.26\right)$, of which the pooled RR (95\% CI) was $0.29(0.16-0.53)$.

Among the cohort studies, the pooled RR (95\% $\mathrm{CI}$ ) of the estimates from those with higher quality (NOS $>5$; three studies) was 0.37 (0.20-0.72), against $0.17(0.07-0.40)$ from those with lower quality (NOS $\leq 5$; two studies). Within each group, no significant heterogeneity was observed ( $\mathrm{p}>0.1)$.

The pooled RR (95\% CI) of the estimates from the three studies with PPI exposure longer than 2 months was $0.28(0.17-0.49)$, against $0.25(0.13-0.50)$ from the four studies with PPI exposure longer than 7 days. Significant heterogeneity was absent in the former group $(\mathrm{p}=0.41)$, but present in the latter $(\mathrm{p}<0.001)$.

\section{Sensitivity analysis}

The sensitivity analysis showed that the direction of the effect of the use of PPIs on peptic ulcer was not influenced by any single study. Exclusion of any single study, except for the study by Yamamoto et al. (50), did not change the significance of the heterogeneity across the studies. When the study by Yamamoto et al. (50) was excluded, the estimated total inconsistency $\left(I^{2}\right)$ and the between-study variance $\left(\tau^{2}\right)$ of the remaining studies were zero (the $\mathrm{p}$-value of the $Q$-statistic was 0.55$)$. This indicates that the study by Yamamoto et al. (50) was the single cause of statistical heterogeneity among the studies reporting on peptic ulcer. 
Total articles: $(n=347)$

PubMed: 184

Embase: 141

Cochrane Central Register of

Controlled Trial: 20

Manual search: 2

Stage 1: Scan of titles and abstracts by two independent reviewers
Excluded $(n=317)$

Review, recommendation, guideline or opinion (no original clinical data): 214

No concomitant use of PPIs and aspirin: 17

Concomitant use of other NSAIDs or clopidogrel: 20

No long-term use of aspirin: 3

Ineligible study design/analysis (cross-sectional, cross-over): 4 Lack of comparison between aspirin and aspirin plus PPI: 25

No reported outcome of interest: 15

Case report: 11

Modelling study: 4

Duplicated: 4

Articles requiring full-text review

$$
(n=30)
$$

Stage 2: Review of full-text by two independent reviewers
Excluded $(n=17)$

Review, recommendation, guideline or opinion (no original clinical data): 2

Concomitant use of other NSAIDs or clopidogrel: 2

Lack of comparison between aspirin and aspirin plus PPI: 5

No reported outcome of interest: 3

No information on whether aspirin was concomitantly used with other NSAIDs or clopidogrel: 1

Concomitant use of antibiotics with PPI for eradication of Helicobacter pylori: 1

Only patients with a history of peptic ulcer or ulcer complications included: 3

\section{Articles meeting criteria for} complete data extraction

$$
(n=13)
$$

(RCT: 2; Case-control: 3; Cohort: 8)

Figure 1 Flow chart of study selection

Publication bias

Egger's regression test showed a tendency of publication bias $(p=0.07)$. The funnel plot (Figure $3 \mathrm{~A}$ ) showed one study lying outside the triangle and an absence of small-size studies reporting smaller beneficial effects of PPI co-therapy on the risk of peptic ulcer. 


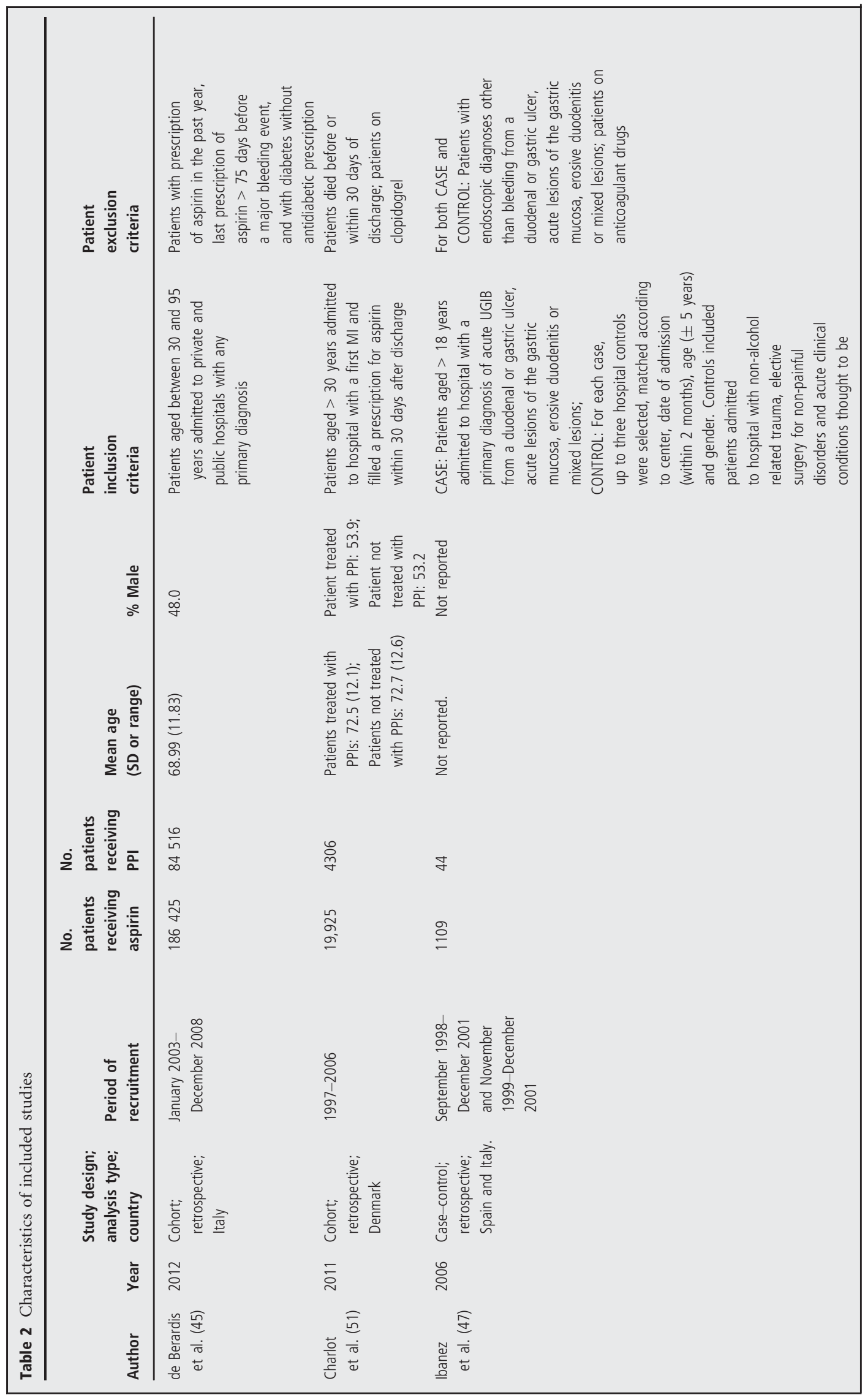




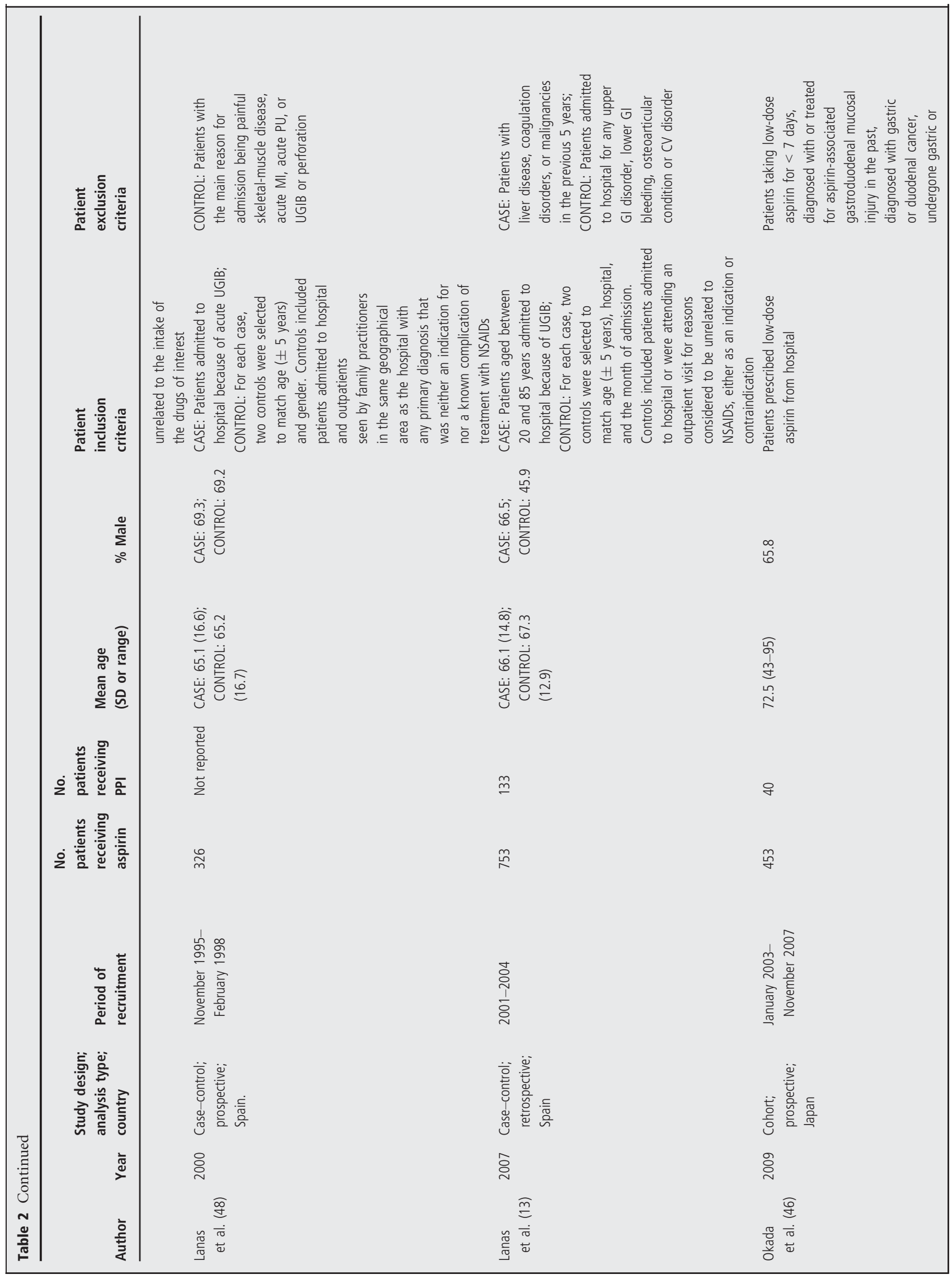




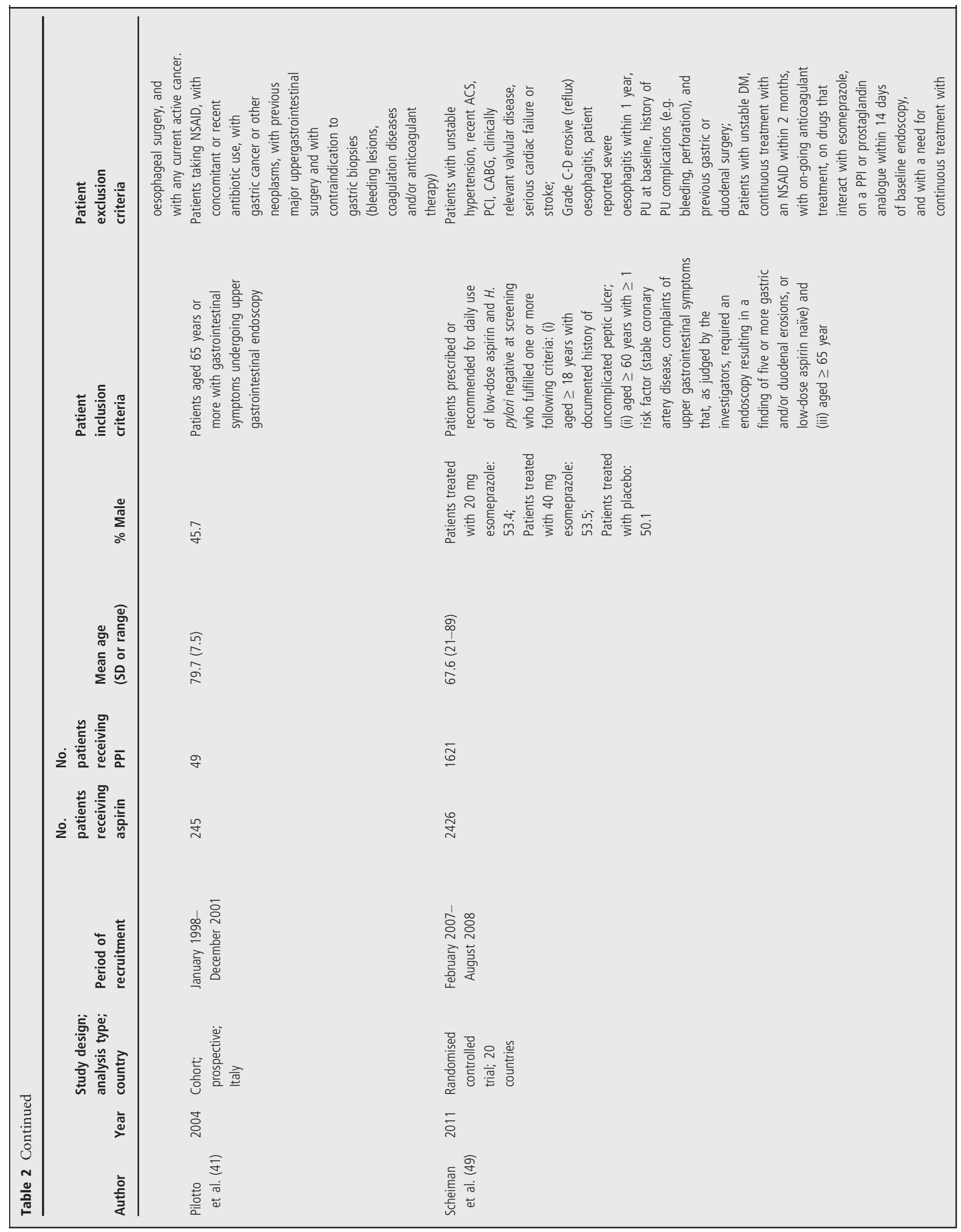




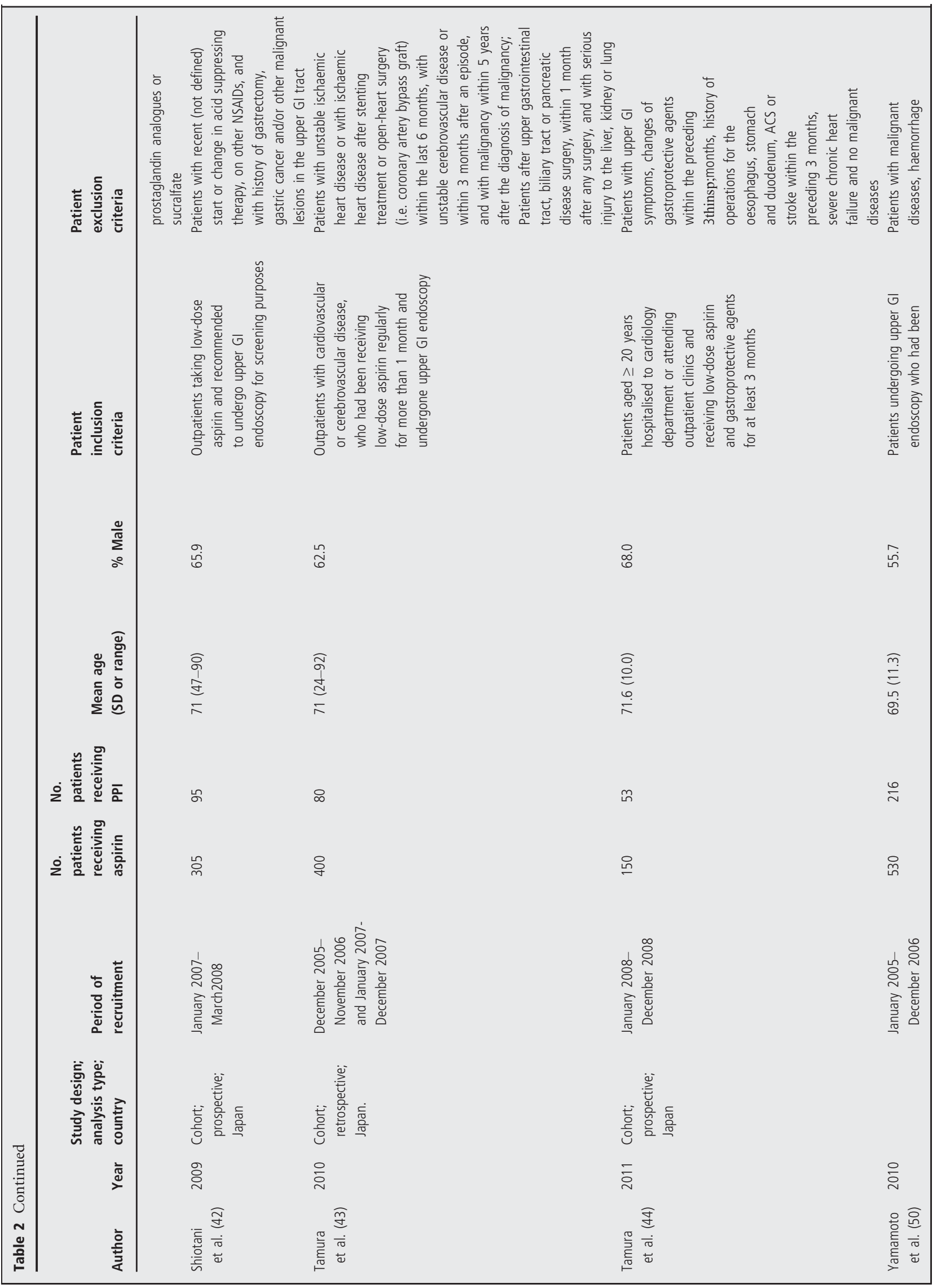




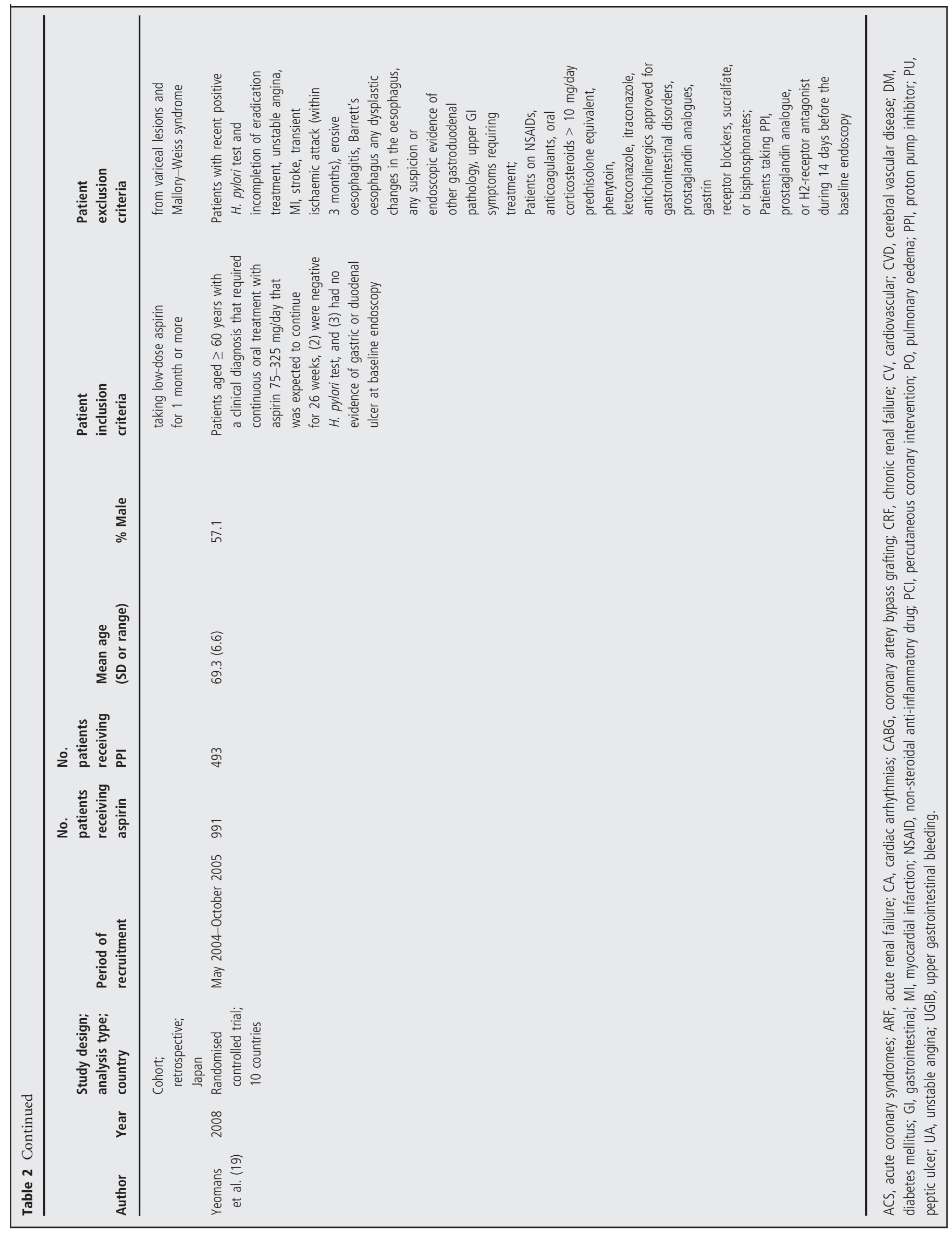




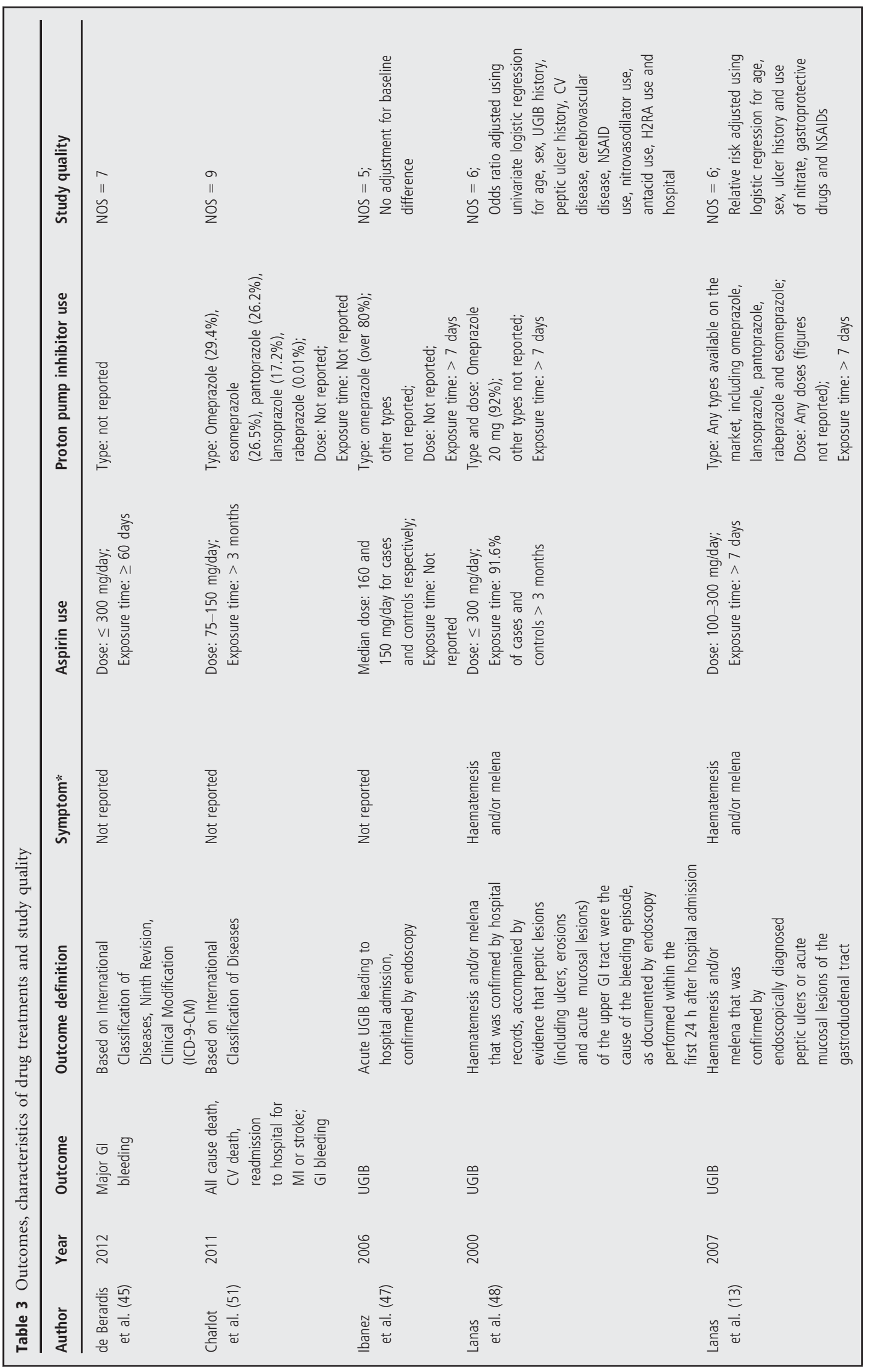




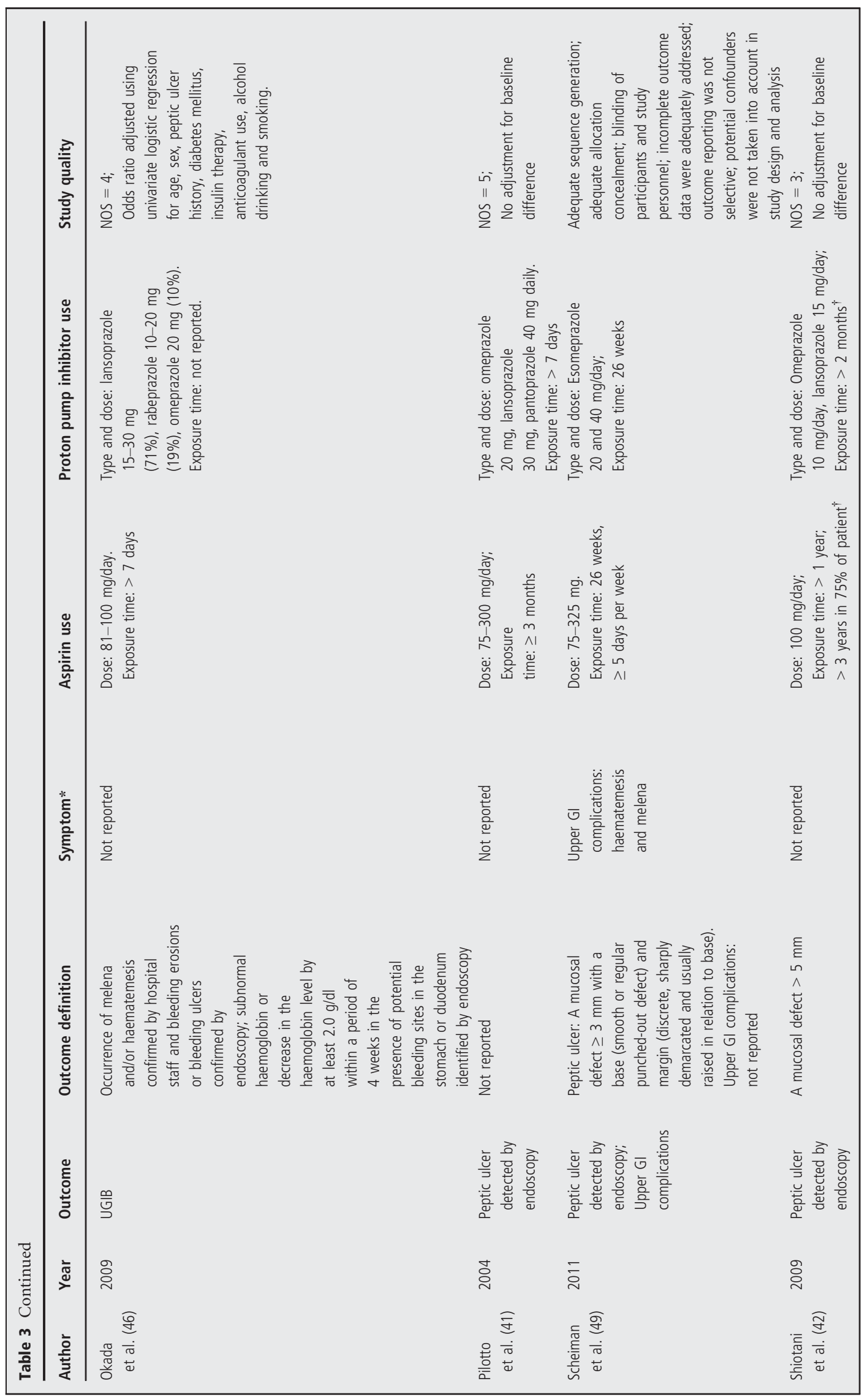




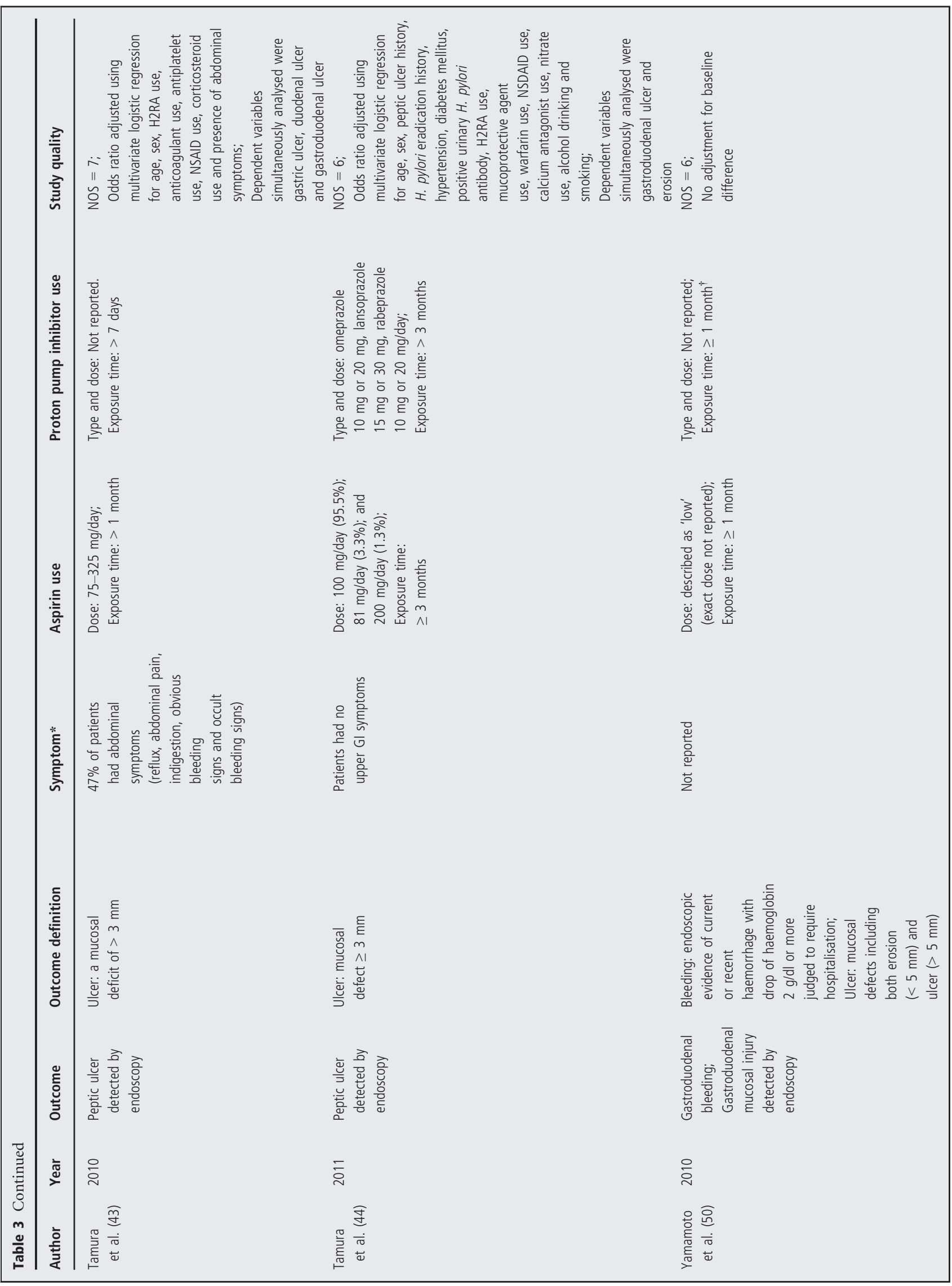




\section{Impact of PPIs on gastrointestinal bleeding}

\section{Pooled effect}

Two RCTs and seven observational (four cohort, three case-control) studies reported on the effect on GI bleeding. Four $(13,46,48,51)$ of the observational studies adjusted the effect estimates for potential confounding. A total number of 399360 patients (> 175886 patients on PPIs; one article (48) did not report the number of PPI users) were included in the analysis. Except for the study by Charlot et al. $(\mathrm{RR}=1.02) \quad(51)$, the directions of the estimated RRs were consistently in favour of PPI use in all studies. However, the 95\% CIs of the RRs in five studies (three and two reported on GI bleeding and UGIB respectively) contained 1.0. When all the estimates were pooled, concomitant use of PPIs was associated with a 50\% risk reduction compared with no PPI therapy (pooled RR $=0.50 ; 95 \% \mathrm{CI}=0.32$ $0.80 ; \mathrm{p}<0.01$; Figure $2 \mathrm{~B})$. The studies were clearly heterogeneous $\left(\mathrm{p}<0.001 ; I^{2}=81.0 \% ; \tau^{2}=0.30\right)$.

\section{Subgroup analysis}

The pooled RR (95\% CI) of the estimates from the two RCTs was $0.41(0.12-1.40)$. No significant heterogeneity between these trials was detected $(\mathrm{p}=0.75$; $\left.I^{2}=0.0 \% ; \tau^{2}=0\right)$. In contrast, there was heterogeneity across the seven observational studies $(\mathrm{p}<0.001$; $\left.I^{2}=86.6 \% ; \tau^{2}=0.35\right)$, of which the pooled RR (95\% CI) was $0.51(0.30-0.85)$.

Among the observational studies, the pooled RR (95\% CI) of the outcomes from five studies with higher quality (NOS $>5$ ) was 0.52 (0.28-0.96), against $0.33(0.05-2.22)$ in the two studies with lower quality $(\mathrm{NOS} \leq 5)$. Significant heterogeneity was present across the high as well as low quality studies $\left(\mathrm{p}<0.05 ; I^{2}>70 \%\right)$.

Because exact PPI exposure time was reported in only two studies, we could not perform subgroup analysis based on this criterion.

\section{Sensitivity analysis}

The sensitivity analysis showed that the direction of the effect of the use of PPIs on GI bleeding, and the presence of heterogeneity were not influenced by any single study. When the studies that did not specify the location of GI bleeding were excluded, the pooled RR (95\% CI) of the estimates from the remaining studies (reporting on UGIB) was 0.36 (0.22-0.57), indicating an effect markedly larger than that observed in all studies combined $(\mathrm{RR}=0.50)$.

\section{Publication bias}

Egger's regression test showed significant publication bias $(p=0.04)$. This is in agreement with the funnel

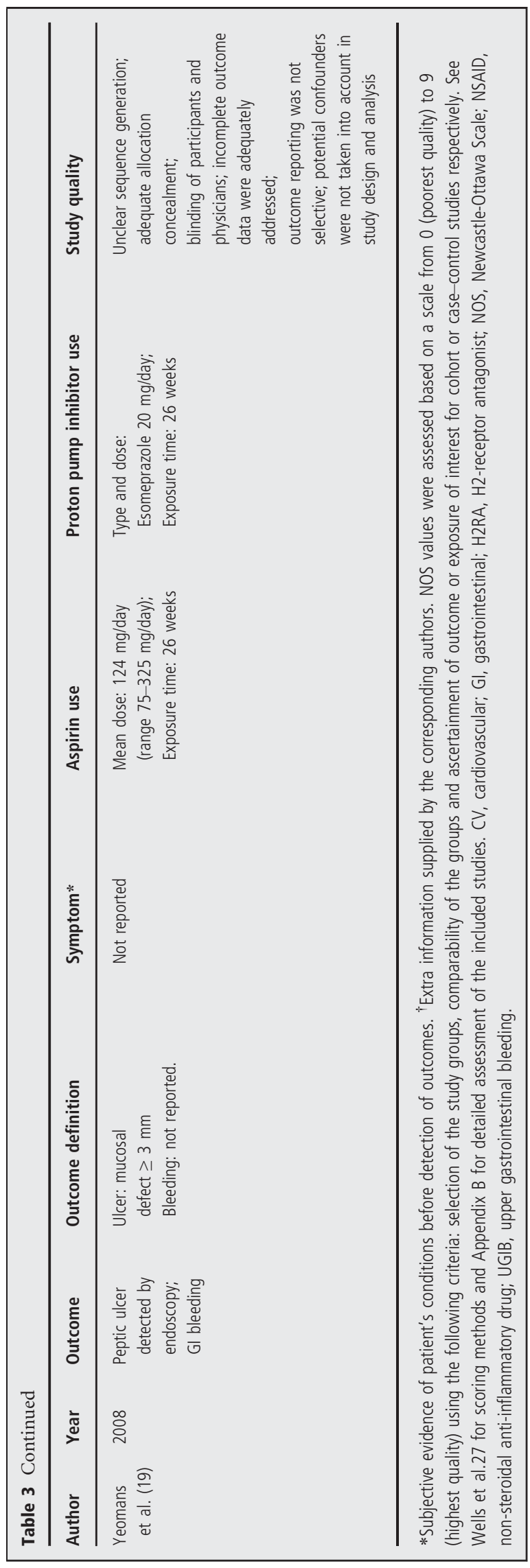


(A) Outcome: Peptic ulcer

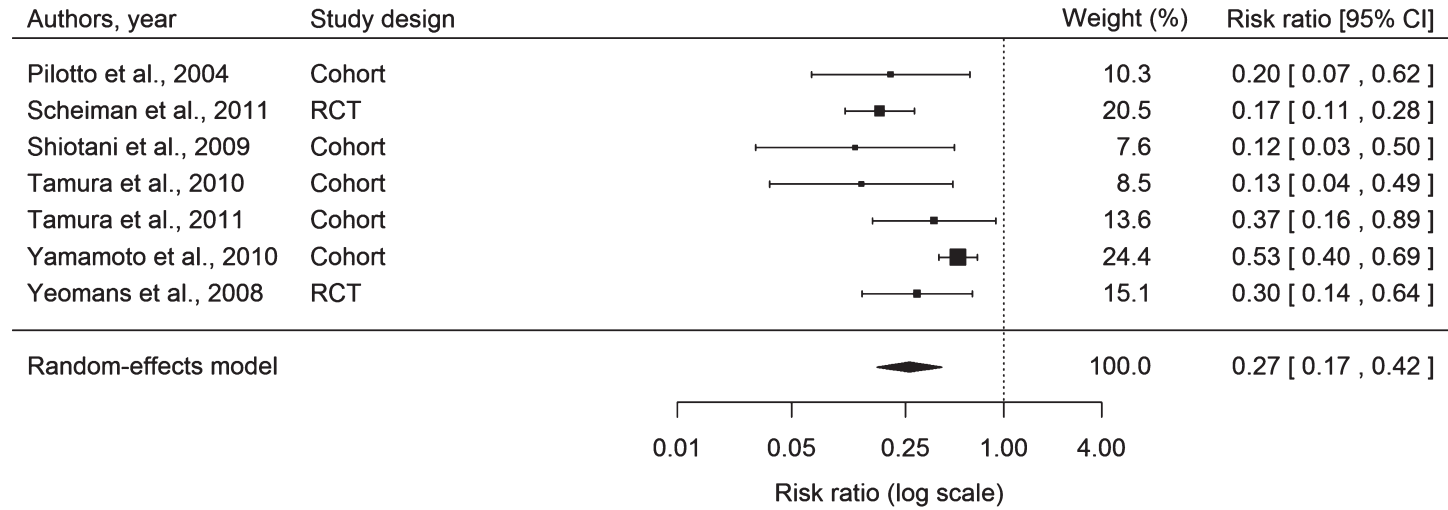

(B) Outcome: Gastrointestinal (GI) bleeding

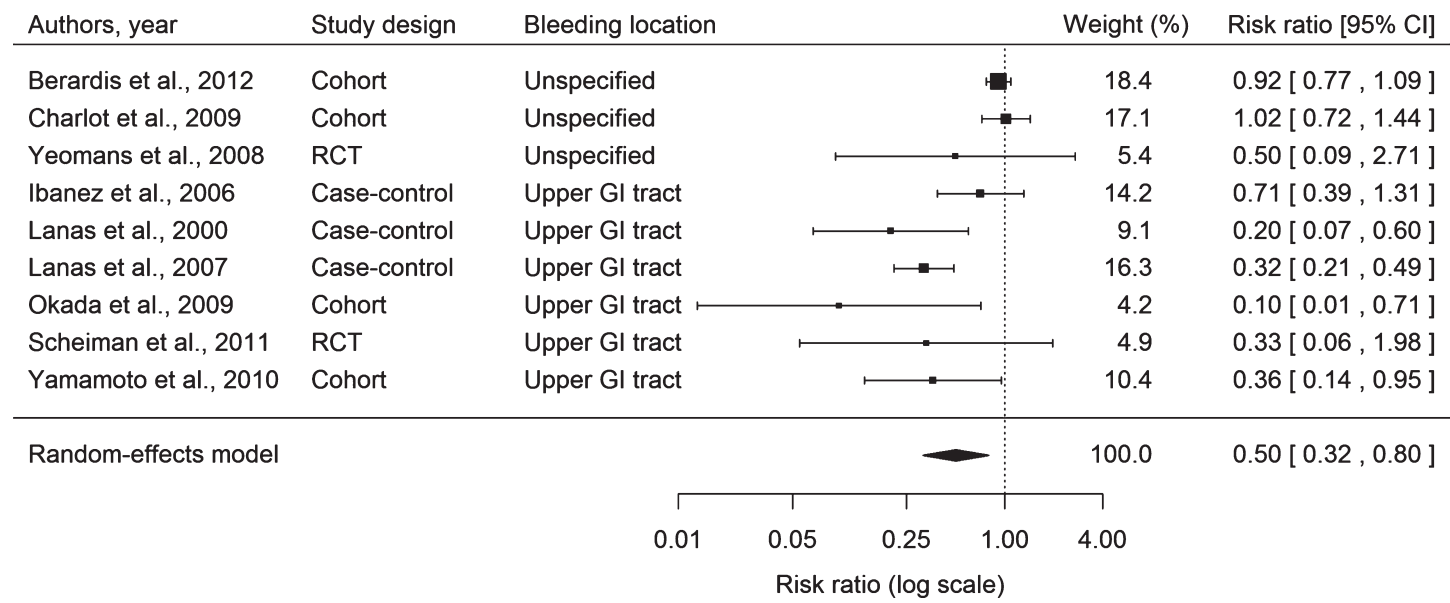

Figure 2 Forest plots of relative risk of (A) peptic ulcer and (B) gastrointestinal (GI) bleeding in patients receiving lowdose aspirin and proton pump inhibitors compared with patients receiving only low-dose aspirin. RCT, randomised controlled trial

plot (Figure 3B), which showed an absence of smallsize studies reporting smaller or no beneficial effect of PPI co-therapy on the risk of UGIB.

\section{Impact of PPIs on cardiovascular events}

Only the cohort study by Charlot et al. (51) reported on CV events and therefore no meta-analysis of the effect of PPIs on CV risk could be performed. In this study, adjusted hazard ratios were computed using a propensity score matched Cox proportional hazards model. The estimated RRs (95\% CIs) of myocardial infarction, stroke and CV death were 1.33 (1.13-1.56), $1.20(0.99-1.46)$ and $2.19(1.92-2.49)$ respectively.

\section{Discussion}

\section{Impact of PPIs on peptic ulcer}

The current meta-analysis showed that concomitant PPI use in patients receiving low-dose aspirin confers a $73 \%$ reduced risk of peptic ulcer. However, the clinical significance of this effect is questionable. Peptic ulcer in all seven included studies were detected by endoscopy, but the associated symptoms were not reported in five of these studies. One study was conducted in asymptomatic patients (44) and another reported that only $47 \%$ of patients had abdominal symptoms (43).

The pooled effect of PPIs on peptic ulcer should be interpreted with caution. The presence of significant heterogeneity indicates that this estimate may be biased. There was methodological diversity as we included both RCTs and cohort studies. Quality assessment of the studies revealed clinical heterogeneity in the treatments and baseline characteristics of the included patients. For example, the inclusion criterion on the minimal exposure time of the patients to aspirin and PPIs differed considerably between the observational studies, ranging from 7 days to 1 year for aspirin use and from 7 days to 3 months for PPI use. Types and doses of PPIs also differed between 


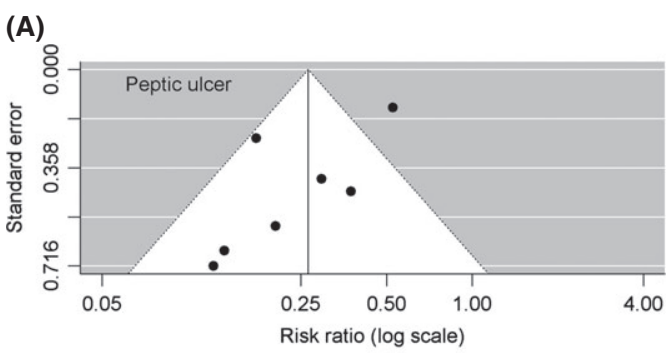

(B)

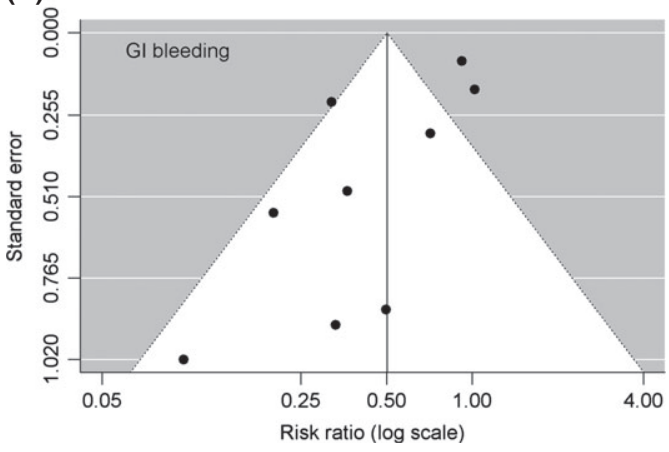

Figure 3 Funnel plots for detection of possible bias of publication on the effect of co-administration of proton pump inhibitors on (A) peptic ulcer and (B)

gastrointestinal (GI) bleeding in patients receiving longterm low-dose aspirin for prevention of cardiovascular events. In each funnel plot, the standard errors of the estimated risk ratios (RRs) were put on a reversed scale, and the triangle was centered on the pooled RR and extending to 1.96 times the standard errors on either side. These plots show a tendency of publication bias because in the absence of bias otherwise, the scatter of the data points would be subject to sampling variation alone and the plots should resemble symmetrical inverted funnels, which is not the case

studies. One study (41) selected only patients older than 65 years while the others included patients with different age ranges (min age, 18; max age, 92) and averages (67.4-79.7). The patient profiles of CV risk factors also varied across studies, partly because three studies $(41,42,50)$ did not exclude patients at very high CV risk while the others did. Age and the presence of $\mathrm{CV}$ risk factors may be confounders as they are likely to be associated with increased risks of GI events as well as with PPI use (52-56). Other potential confounders include a history of peptic ulcer disease $(43,46,48,57)$ and lower socioeconomic status; the latter is associated with Helicobacter pylori infection and the risk of peptic ulcer disease (58-60), and also with less access to healthcare resources and thus PPIs. Importantly, among five cohort studies, only two adjusted estimates for baseline differences and therefore potential confounders, including age and peptic ulcer history $(43,44)$. Cardiovascular risk factors and socioeconomic status were not considered as potential confounders in any study.
Among the cohort studies, the pooled RR of the estimates from those with higher quality was considerably higher than that from those with lower quality (0.37 vs. 0.17). This implies that low-quality studies tended to publish results representing large beneficial effect of PPIs. In line with this, the funnel plot indicated an absence of small-size studies reporting small beneficial effect of PPIs. Despite the presence of heterogeneity and low number of studies, the direction of the effects in all studies and of the pooled effects in all subgroups is consistent $(<0.55)$, with all the upper bounds of the 95\% CIs smaller than 1.0. These observations suggest a plausibly beneficial effect of co-therapy with PPIs on the risk of peptic ulcer in patients receiving long-term low-dose aspirin.

These findings on the impact of PPIs on peptic ulcer argue in favour of, but may be insufficient to justify the co-administration of PPIs. First, the clinical relevance of peptic ulcer prevention is unclear because peptic ulcer is a poor predictor of ulcer complications $(61,62)$ and can remain asymptomatic $(44,63)$. In addition, only seven studies, of which five were observational, were included in the meta-analysis. In observational studies, it is difficult to fully prevent or account for confounding, and, unfortunately, most studies included in our analysis failed to appropriately adjust for confounders.

\section{Impact of PPIs on gastrointestinal bleeding}

The current meta-analysis showed that concomitant use of PPIs in patients receiving low-dose aspirin corresponds to a $50 \%$ and $64 \%$ reduced risk of GI bleeding and UGIB respectively. Again, this finding should be interpreted with caution. There was methodological diversity in study design, and clinical heterogeneity in the treatments and baseline characteristics of the included patients. RCTs, case-control and cohort studies were all included in the meta-analysis. The inclusion criterion on the minimal exposure time of aspirin and PPIs differed between studies, ranging from 7 days to 6 months. The specific type of PPIs was not reported in more than half of the included studies, and differed between studies that report these data. Except for the study by Scheiman et al. (49), which included only patients with a negative $H$. pylori test, none of the studies took the status of $H$. pylori infection into account. Helicobacter pylori infection may be a confounder, because it is associated with both the risk of UGIB and the use of PPIs in eradication therapy (64). Because the duration of PPI exposure was not reported in two observational studies $(46,47)$, it is not clear whether PPI use in these studies was because of $H$. pylori eradication (short-term) or treatment of peptic ulcer disease (longterm). Among five-observational studies that reported on UGIB, only three studies adjusted the estimates for 
potential confounders, including age and peptic ulcer history $(13,46,48)$. Importantly, no studies adjusted the estimates for other major potential confounders, such as H. pylori infection, CV risk factors and socioeconomic status.

As in the case of peptic ulcer, these findings on the impact of PPIs on the risk of GI events may not be sufficient to justify the use of PPIs in patients on long-term aspirin therapy. Only six studies reporting on UGIB, of which five were observational, were included in the meta-analysis. Although the findings overall indicate a beneficial effect of adding PPIs to aspirin on the risk of GI bleedings, the directions of the 95\% CIs of the estimated RRs were not consistent across all studies. This observation, together with the evidence of publication bias, indicates that the magnitude of the beneficial effect of PPIs on GI bleeding remains uncertain.

\section{Impact of PPIs on cardiovascular events}

Because only one study on the effect of PPIs on CV risk was found (51), we could not perform a metaanalysis of this effect. Hypothetically, PPIs might affect aspirin bioavailability by raising gastric $\mathrm{pH}$ and therefore attenuate the antiplatelet effect of aspirin. Only a few studies tested the latter hypothesis and showed contradictory results $(32,65-67)$. The clinical significance of these hypotheses has recently also been seriously challenged (33). We found only one study that investigated this clinical significance. In this large retrospective cohort study (51), propensity scores were used to reduce bias in the estimated effect because of confounding factors (68). While residual confounding was considered unlikely, the authors acknowledged that it could not be excluded that the effect of PPIs might be confounded by a number of uncontrolled factors such as lipid levels, body mass index and smoking, on which there was no information (51). In addition, comorbidities that were not considered but might act as confounders in this study included severe reflux and Barrett's oesophagus; patients with these diseases are often prescribed PPIs and are at a high risk of CV death (69). Currently, the clinical impact of PPIs on the effect of aspirin on $\mathrm{CV}$ risk therefore remains uncertain.

\section{Study limitations and the need for further research}

Our study has some limitations. Because of the low number of the included studies, we pooled data from both RCTs and observational studies. Three casecontrol studies (reporting on UGIB) $(13,47,48)$ were not nested case-control studies (70) and therefore we considered the odds ratio as RRs (71) assuming that UGIB is a rare event (5). In four observational stud- ies $(42,45,47,50)$, neither relevant RRs nor relevant odds ratios were provided and we calculated the RRs using the reported number of events in the groups with and without a PPI therapy; in this way, it was not possible to adjust the RRs for differences in the patient baseline characteristics in these two groups.

In this study, we used the random-effects models to estimate the mean true effects in a hypothetical population of studies from which, the studies we found were assumed to be a random sample (72). Because the number of the included studies was relatively small, the estimates of the between-study variances $\left(\tau^{2}\right)$, and hence of the pooled effects and their confidence intervals, may not be precise when using the random-effects models $(35,72)$. Additional metaanalyses using fixed-effects models showed that the pooled RRs obtained from the fixed-effects models ( 0.37 for peptic ulcer and 0.77 for GI bleeding) were slightly larger than those obtained from the randomeffects models. The 95\% CIs of the pooled RRs from the fixed-effects models $[(0.30-0.45)$ for peptic ulcer and (0.68-0.89) for GI bleeding] were narrower, but both the lower and upper bounds were larger than those from the random-effects models. Thus, the random- and fixed-effects models produced similar results.

Despite the claim that inclusion of unpublished studies may help to avoid publication bias, we did not include unpublished studies because this inclusion can itself introduce bias for several reasons. First, the studies that can be retrieved may not be representative of all unpublished studies. Second, the quality of unpublished studies, given a lack of peer review, may be lower than that of published studies. Finally, data provided by the study investigators may not be complete and this may depend on whether or not the results are favourable (35). Besides the arguments above, there is also a practical reason to not include unpublished research. To ensure that the inclusion of unpublished studies does not cause bias, an exhaustive, manual search should be made to retrieve all relevant studies. In addition, a detailed and critical appraisal of the unpublished studies should be performed. There are numerous national and international registers and therefore a lot of time would be needed to search these sources, retrieve the documents and critically appraise the studies.

The current literature review showed that published studies on the impact of PPIs on the GI and $\mathrm{CV}$ outcomes in aspirin users were limited in both quantity and quality. Given the large number of patients concomitantly prescribed aspirin and PPIs, there is an urgent need for further studies on this topic. The clinical significance of peptic ulcer prevention in asymptomatic patients should be rigorously 
clarified. Also, more studies on the impact of PPIs on CV events and new studies on the effect of PPIs on aspirin adherence should be conducted. In addition, any possible long-term side effects of PPI cotherapy in patients receiving low-dose aspirin should be carefully reviewed and/or further investigated. A recent large study in 210155 patients showed that the use of PPIs for two or more years was significantly associated with vitamin $\mathrm{B}_{12}$ deficiency (73). Long-term therapy with PPI might also be associated with increased risks of fracture (74), pneumonia (75), enteric infection (76) and hypomagnesaemia (77), but more evidence is needed to confirm (or refute) these associations.

Since the risks of adverse GI events differ in various patient groups (78), studies should also focus on the benefit-risk ratios of co-administration of PPIs in particular patient groups with different risk factors. Given that long-term use of PPIs is costly, co-therapy with PPIs should be viewed also from a health economic perspective. For this, a pharmacoeconomic study is needed to provide comprehensive information on the clinical, quality of life and cost-consequences of co-prescribing PPIs for decision makers.

\section{Conclusions}

Our study shows that the practice of co-prescribing PPIs in patients taking low-dose aspirin is supported by some data in the literature, but the evidence remains weak. It is currently unclear whether the benefits of co-administration of PPIs in users of lowdose aspirin outweigh the potential harms. Stronger evidence is needed to advise patients and inform decision makers.

\section{Acknowledgements}

This study was financially supported by The Netherlands Organization for Health Research and Development (ZonMw; Rational Pharmacotherapy Program; Project number 836021018). The funder had no role in the design of the study, the collection, analysis and interpretation of data, or the writing of the manuscript and the decision to submit it for publication.

\section{Author contributions}

CDAS, AWH and ATD: study concept; ATD, AWH, CDAS and MAJ: study design; ATD and FHV: acquisition and analysis of data; All authors: interpretation of results; ATD: drafting of the manuscript; All authors: Critically revision and approval of the final version of the manuscript for publication.

\section{References}

1 Forgacs I, Loganayagam A. Overprescribing proton pump inhibitors is expensive and not evidence based. BMJ 2008; 336: 2.

2 Ladd AM, Panagopoulos G, Cohen J, Mar N, Graham R. Potential costs of inappropriate use of proton pump inhibitors. Am J Med Sci 2014; 347: 446-51.

3 Yeomans ND, Lanas AI, Talley NJ et al. Prevalence and incidence of gastroduodenal ulcers during treatment with vascular protective doses of aspirin. Aliment Pharmacol Ther 2005; 22: 795-801.

4 Weil J, Colin-Jones D, Langman M et al. Prophylactic aspirin and risk of peptic ulcer bleeding. $B M J$ 1995; 310: 827-30

5 Derry S, Loke YK. Risk of gastrointestinal haemorrhage with long term use of aspirin: meta-analysis. BMJ 2000; 321: 1183-7.

6 Garcia Rodriguez LA, Hernandez-Diaz S, de Abajo FJ. Association between aspirin and upper gastrointestinal complications: systematic review of epidemiologic studies. Br J Clin Pharmacol 2001; 52: 563-71.

7 Serebruany VL, Steinhubl SR, Berger PB et al. Analysis of risk of bleeding complications after different doses of aspirin in 192,036 patients enrolled in 31 randomized controlled trials. Am J Cardiol 2005; 95: 1218-22.

8 Bhatt DL, Scheiman J, Abraham NS et al. ACCF/ ACG/AHA 2008 expert consensus document on reducing the gastrointestinal risks of antiplatelet therapy and NSAID use: a report of the American College of Cardiology Foundation Task Force on Clinical Expert Consensus Documents. J Am Coll Cardiol 2008; 52: 1502-17.

9 Hamm CW, Bassand J-P, Agewall S et al. ESC Guidelines for the management of acute coronary syndromes in patients presenting without persistent ST-segment elevation The Task Force for the management of acute coronary syndromes (ACS) in patients presenting without persistent ST-segment elevation of the European Society of Cardiology (ESC). Eur Heart J 2011; 32: 2999-3054.

10 Cooper A, Skinner J, Nherera L et al. Clinical Guidelines and Evidence Review for Post Myocardial Infarction: Secondary Prevention in Primary and Secondary Care for Patients Following a Myocardial Infarction. London: National Collaborating Centre for Primary Care and Royal College of General Practitioners. NICE clinical guideline number 48; 2007. www.nice.org.uk/guidance/CG48 (accessed 9 November 2013).

11 Barkun AN, Bardou M, Kuipers EJ et al. International consensus recommendations on the management of patients with nonvariceal upper gastrointestinal bleeding. Ann Intern Med 2010; 152: 101-13.

12 Numans ME, De Wit NJ, Dirven JAM et al. NHGStandaard Maagklachten (tweede herziening). Huisarts Wet 2013; 56: 26-35.

13 Lanas A, García-Rodríguez LA, Arroyo MT et al. Effect of antisecretory drugs and nitrates on the risk of ulcer bleeding associated with nonsteroidal anti-inflammatory drugs, antiplatelet agents, and anticoagulants. Am J Gastroenterol 2007; 102: $507-$ 15.

14 Chin MWS, Yong G, Bulsara MK, Rankin J, Forbes GM. Predictive and protective factors associated with upper gastrointestinal bleeding after percutaneous coronary intervention: a case-control study. Am J Gastroenterol 2007; 102: 2411-6.

15 Lanas A, Rodrigo L, Marquez JL et al. Low frequency of upper gastrointestinal complications in a cohort of high-risk patients taking low-dose aspirin or NSAIDS and omeprazole. Scand J Gastroenterol 2003; 38: 693-700.

16 Lai KC, Lam SK, Chu KM et al. Lansoprazole for the prevention of recurrences of ulcer complications from long-term low-dose aspirin use. $N$ Engl J Med 2002; 346: 2033-8.

17 Chan FKL, Ching JYL, Hung LCT et al. Clopidogrel versus aspirin and esomeprazole to prevent recurrent ulcer bleeding. $N$ Engl J Med 2005; 352: 238-44.

18 Lai KC, Chu KM, Hui WM et al. Esomeprazole with aspirin versus clopidogrel for prevention of recurrent gastrointestinal ulcer complications. Clin Gastroenterol Hepatol 2006; 4: 860-5.

19 Yeomans N, Lanas A, Labenz J et al. Efficacy of esomeprazole (20 $\mathrm{mg}$ once daily) for reducing the risk of gastroduodenal ulcers associated with continuous use of low-dose aspirin. Am J Gastroenterol 2008; 103: 2465-73. 
20 Smith SC, Blair SN, Bonow RO et al. AHA/acc guidelines for preventing heart attack and death in patients with atherosclerotic cardiovascular disease: 2001 update a statement for healthcare professionals from the American Heart Association and the American College of Cardiology. Circulation 2001; 104: 1577-9.

21 Pearson TA, Blair SN, Daniels SR et al. AHA guidelines for primary prevention of cardiovascular disease and stroke: 2002 update consensus panel guide to comprehensive risk reduction for adult patients without coronary or other atherosclerotic vascular diseases. Circulation 2002; 106: 388-91.

22 Smith SC, Allen J, Blair SN et al. AHA/ACC guidelines for secondary prevention for patients with coronary and other atherosclerotic vascular disease: 2006 update: endorsed by the National Heart, Lung, and Blood Institute. J Am Coll Cardiol 2006; 47: 2130-9.

23 Smith SC, Benjamin EJ, Bonow RO et al. AHA/ ACCF secondary prevention and risk reduction therapy for patients with coronary and other atherosclerotic vascular disease: 2011 update: a guideline from the American Heart Association and American College of Cardiology Foundation endorsed by the World Heart Federation and the Preventive Cardiovascular Nurses Association. J Am Coll Cardiol 2011; 58: 2432-46.

24 Perk J, De Backer G, Gohlke $\mathrm{H}$ et al. European Guidelines on cardiovascular disease prevention in clinical practice (version 2012) The Fifth Joint Task Force of the European Society of Cardiology and Other Societies on Cardiovascular Disease Prevention in Clinical Practice (constituted by representatives of nine societies and by invited experts) Developed with the special contribution of the European Association for Cardiovascular Prevention \& Rehabilitation (EACPR). Eur Heart J 2012; 33: 1635-701.

25 British Cardiac Society, British Hypertension Society, Diabetes UK, HEART UK, Primary Care Cardiovascular Society, The Stroke Association. JBS 2: Joint British Societies' guidelines on prevention of cardiovascular disease in clinical practice. Heart 2005; 91: v1-52.

26 World Health Organization. Prevention of Cardiovascular Disease: Guideline for Assessment and Management of Cardiovascular Risk. Geneva: WHO, 2007.

27 Janssen M, Dijkmans BA, Vandenbroucke JP, Biemond I, Lamers CB. Achlorhydria does not protect against benign upper gastrointestinal ulcers during NSAID use. Dig Dis Sci 1994; 39: 362-5.

28 Wallace JL. How do NSAIDs cause ulcer disease? Best Pract Res Clin Gastroenterol 2000; 14: 147-59.

29 Wallace JL, Tigley AW. Review article: new insights into prostaglandins and mucosal defence. Aliment Pharmacol Ther 1995; 9: 227-35.

30 Scheiman JM. NSAIDs, gastrointestinal injury, and cytoprotection. Gastroenterol Clin North Am 1996; 25: 279-98.

31 Giraud MN, Sanduja SK, Felder TB, Illich PA, Dial EJ, Lichtenberger LM. Effect of omeprazole on the bioavailability of unmodified and phospholipidcomplexed aspirin in rats. Aliment Pharmacol Ther 1997; 11: 899-906.

32 Würtz M, Grove EL, Kristensen SD, Hvas AM. The antiplatelet effect of aspirin is reduced by proton pump inhibitors in patients with coronary artery disease. Heart 2010; 96: 368-71.
33 Würtz M, Grove EL. Combining aspirin and proton pump inhibitors: for whom the warning bell tolls? Expert Opin Drug Metab Toxicol 2012; 8: 1051-5.

34 Wells GA, Shea B, O'connell D et al. The Newcastle-Ottawa Scale (NOS) for assessing the quality of nonrandomised studies in meta-analyses; 2012. http://www.ohri.ca/programs/clinical_epidemiology/ oxford.asp (accessed 1 January 2014).

35 Higgins JPT, Green S, (eds). Cochrane Handbook for Systematic Reviews of Interventions: Version 5.1.0. The Cochrane Collaboration; 2011. http:// www.cochrane-handbook.org (accessed 24 December 2014).

36 Walker A. Observation and Inference: An Introduction to the Methods of Epidemiology. Newton Lower Falls: Epidemiology Resources Inc, 1991.

37 Higgins J, Thompson SG. Quantifying heterogeneity in a meta-analysis. Stat Med 2002; 21: 1539-58.

38 Higgins J, Thompson SG, Deeks JJ, Altman DG. Measuring inconsistency in meta-analyses. BMJ 2003; 327: 557-60.

39 Egger M, Smith GD, Schneider M, Minder C. Bias in meta-analysis detected by a simple, graphical test. BMJ 1997; 315: 629-34.

40 Viechtbauer W. Conducting meta-analyses in $\mathrm{R}$ with the metafor package. J Stat Softw 2010; 36: 1-48.

41 Pilotto A, Franceschi M, Longoa MG et al. Helicobacter pylori infection and the prevention of peptic ulcer with proton pump inhibitors in elderly subjects taking low-dose aspirin. Dig Liver Dis 2004; 36: 666-70.

42 Shiotani A, Sakakibara T, Yamanaka Y et al. Upper gastrointestinal ulcer in Japanese patients taking low-dose aspirin. J Gastroenterol 2009; 44: 126-31.

43 Tamura I, Fujita T, Tsumura $\mathrm{H}$ et al. Low-dose aspirin-induced gastroduodenal mucosal injury in Japanese patients with arteriosclerotic disease. Intern Med 2010; 49: 2537-45.

44 Tamura A, Murakami K, Kadota J. Prevalence and independent factors for gastroduodenal ulcers/erosions in asymptomatic patients taking low-dose aspirin and gastroprotective agents: the OITA-GF study. QJM 2011; 104: 133-9.

45 De Berardis G, Lucisano G, D’Ettorre A et al. Association of aspirin use with major bleeding in patients with and without diabetes. JAMA 2012; 307: 2286-94.

46 Okada K, Inamori M, Imajo K et al. Clinical study of upper gastrointestinal bleeding associated with low-dose aspirin in Japanese patients. Hepatogastroenterology 2009; 56: 1665-9.

47 Ibanez L, Vidal X, Vendrell L, Moretti U, Laporte JR. Upper gastrointestinal bleeding associated with antiplatelet drugs. Aliment Pharmacol Ther 2006; 23: 235-42.

48 Lanas A, Bajador E, Serrano P et al. Nitrovasodilators, low-dose aspirin, other nonsteroidal antiinflammatory drugs, and the risk of upper gastrointestinal bleeding. N Engl J Med 2000; 343: 834-9.

49 Scheiman JM, Devereaux PJ, Herlitz J et al. Prevention of peptic ulcers with esomeprazole in patients at risk of ulcer development treated with low-dose acetylsalicylic acid: a randomised, controlled trial (OBERON). Heart 2011; 97: 797-802.

50 Yamamoto T, Isono A, Mishina Y et al. Gastroduodenal mucosal injury in patients taking low-dose aspirin and the role of gastric mucoprotective drugs: possible effect of rebamipide. J Clin Biochem Nutr 2010; 47: 27-31.

51 Charlot M, Grove EL, Hansen PR et al. Proton pump inhibitor use and risk of adverse cardiovascular events in aspirin treated patients with first time myocardial infarction: nationwide propensity score matched study. BMJ 2011; 342: d2690.

52 Taylor DN, Blaser MJ. The epidemiology of Helicobacter pylori infection. Epidemiol Rev 1991; 13: 42-59.

53 van Zanten SJOV, Pollak PT, Best LM, Bezanson GS, Marrie T. Increasing prevalence of Helicobacter pylori infection with age: continuous risk of infection in adults rather than cohort effect. J Infect Dis 1994; 169: 434-7.

54 Longstreth GF. Epidemiology of hospitalization for acute upper gastrointestinal hemorrhage: a population-based study. Am J Gastroenterol 1995; 90: 20610.

55 Blower AL, Brooks A, Fenn GC et al. Emergency admissions for upper gastrointestinal disease and their relation to NSAID use. Aliment Pharmacol Ther 1997; 11: 283-91.

56 Knijff-Dutmer EAJ, Schut GA, van de Laar MAFJ. Concomitant coumarin-NSAID therapy and risk for bleeding. Ann Pharmacother 2003; 37: 12-6.

57 Serrano P, Lanas A, Arroyo MT, Ferreira IJ. Risk of upper gastrointestinal bleeding in patients taking low-dose aspirin for the prevention of cardiovascular diseases. Aliment Pharmacol Ther 2002; 16: 1945-53.

58 Sitas F, Forman D, Yarnell JW et al. Helicobacter pylori infection rates in relation to age and social class in a population of Welsh men. Gut 1991; 32: 25-8.

59 Malaty HM, Graham DY. Importance of childhood socioeconomic status on the current prevalence of Helicobacter pylori infection. Gut 1994; 35: $742-5$.

60 Malaty HM, Kim JG, Kim SD, Graham DY. Prevalence of Helicobacter pylori infection in Korean children: inverse relation to socioeconomic status despite a uniformly high prevalence in adults. Am J Epidemiol 1996; 143: 257-62.

61 Jorde R, Bostad L, Burhol PG. Asymptomatic gastric ulcer: a follow-up study in patients with previous gastric ulcer disease. Lancet 1986; 327: 119-21.

62 Laine L, Maller ES, Yu C, Quan H, Simon T. Ulcer formation with low-dose enteric-coated aspirin and the effect of COX-2 selective inhibition: a doubleblind trial. Gastroenterology 2004; 127: 395-402.

63 Jorde R, Burhol P. Asymptomatic peptic ulcer disease. Scand J Gastroenterol 1987; 22: 129-34.

64 Romano M, Cuomo A. Eradication of Helicobacter pylori: a clinical update. MedGenMed 2004; 6: 19.

65 Inarrea P, Esteva F, Cornudella R, Lanas A. Omeprazole does not interfere with the antiplatelet effect of low-dose aspirin in man. Scand J Gastroenterol 2000; 35: 242-6.

66 Niazi M, Andersson T, Naucler E, Sundin M, Naesdal J. Evaluation of the pharmacokinetic interaction between esomeprazole (40 mg) and acetylsalicylic acid $(325 \mathrm{mg}$ ) in healthy volunteers. Int J Clin Pharm Ther 2009; 47: 564-9.

67 Adamopoulos AB, Sakizlis GN, Nasothimiou EG et al. Do proton pump inhibitors attenuate the effect of aspirin on platelet aggregation? A randomized crossover study. J Cardiovasc Pharmacol 2009; 54: 163-8. 
68 Rosenbaum PR, Rubin DB. Reducing bias in observational studies using subclassification on the propensity score. J Am Stat Assoc 1984; 79: 516-24.

69 Moayyedi P, Burch N, Akhta-Danesh N et al. Mortality rates in patients with Barrett's oesophagus. Aliment Pharmacol Ther 2008; 27: 316-20.

70 Ernster VL. Nested case-control studies. Prev Med 1994; 23: 587-90.

71 Pearce N. What does the odds ratio estimate in a case-control study? Int J Epidemiol 1993; 22: 1189 92.

72 Hedges LV, Vevea JL. Fixed- and random-effects models in meta-analysis. Psychol Methods 1998; 3: 486-504.
73 Lam JR, Schneider JL, Zhao W, Corley DA. Proton pump inhibitor and histamine 2 receptor antagonist use and vitamin B12 deficiency. JAMA 2013; 310: 2435-42.

74 Ngamruengphong S, Leontiadis GI, Radhi S, Dentino A, Nugent K. Proton pump inhibitors and risk of fracture: a systematic review and meta-analysis of observational studies. Am J Gastroenterol 2011; 106: 1209-18.

75 Eom CS, Jeon CY, Lim JW, Cho EG, Park SM, Lee KS. Use of acid-suppressive drugs and risk of pneumonia: a systematic review and meta-analysis. Can Med Assoc I 2011; 183: 310-9.
76 Leonard J, Marshall JK, Moayyedi P. Systematic review of the risk of enteric infection in patients taking acid suppression. Am J Gastroenterol 2007; 102: 2047-56.

77 Mackay JD, Bladon PT. Hypomagnesaemia due to proton-pump inhibitor therapy: a clinical case series. QJM 2010; 103: 387-95.

78 Sostres C, Lanas A. Gastrointestinal effects of aspirin. Nat Rev Gastroenterol Hepatol 2011; 8: 385-94.

Paper received September 2014, accepted January 2015

\section{Appendix A. Search strategies}

Table A1 Search queries for PUBMED

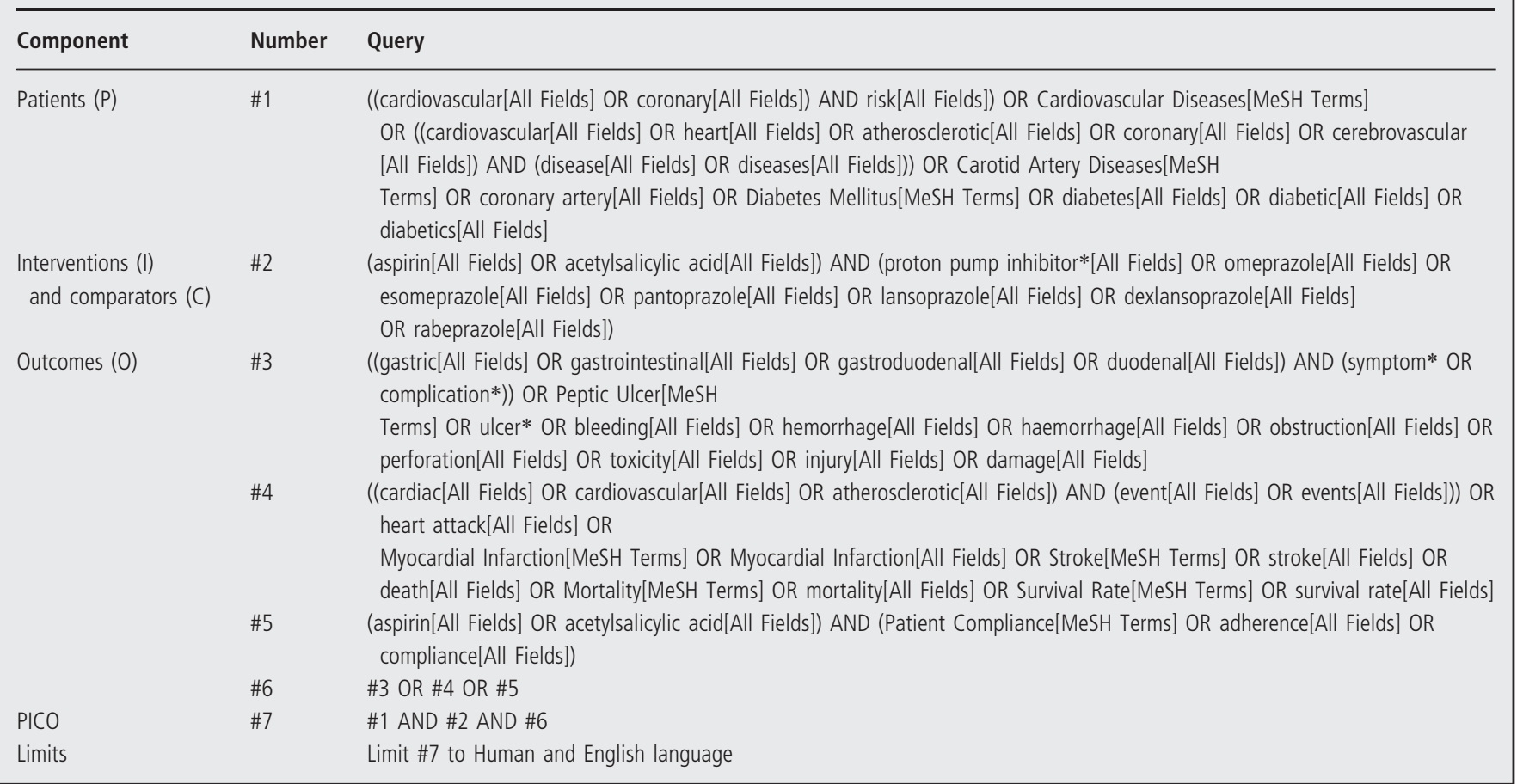


Table A2 Search queries for EMBASE (Ovid)

\begin{tabular}{|c|c|c|}
\hline Component & Number & Query \\
\hline Patients (P) & & $\begin{array}{l}\text { (((cardiovascular or coronary) and risk) or ((cardiovascular or heart or atherosclerotic or coronary or cerebrovascular) and } \\
\text { disease*) or coronary artery or diabet*). ti,ot,sh,ab,kw, tw. }\end{array}$ \\
\hline $\begin{array}{l}\text { Interventions (I) } \\
\text { and comparators (C) }\end{array}$ & 2 & $\begin{array}{l}\text { ((aspirin or acetylsalicylic acid) and (proton pump inhibitor* or omeprazole or esomeprazole or pantoprazole or lansoprazole } \\
\text { or dexlansoprazole or rabeprazole)). ti,ot,sh,ab,kw,tw. }\end{array}$ \\
\hline \multirow[t]{4}{*}{ Outcomes (0) } & 3 & $\begin{array}{l}(((\text { gastric or gastrointestinal or gastroduodenal or duodenal) and (symptom* or complication*)) or ulcer* or bleeding or } \\
\text { hemorrhage or haemorrhage or obstruction or perforation or toxicity or injury or damage). ti,ot,sh,ab,kw,tw. }\end{array}$ \\
\hline & 4 & $\begin{array}{l}\text { (((cardiac or cardiovascular or atherosclerotic) and event*) or heart attack or myocardial infarction or stroke or death or } \\
\text { mortality or survival rate). ti,ot,sh,ab,kw, tw. }\end{array}$ \\
\hline & 5 & ((aspirin or acetylsalicylic acid) and (adherence or compliance)). ti,ot,sh,ab,kw,tw. \\
\hline & 6 & 3 or 4 or 5 \\
\hline PICO & 7 & 1 and 2 and 6 \\
\hline Limits & 8 & limit 7 to Human and English language \\
\hline
\end{tabular}

ti, title; ot, original title; sh, subject headings; ab, abstract; kw, keyword; tw, text word.

Table A3 Search queries for Cochrane Central Register of Controlled Trials

\begin{tabular}{|c|c|c|}
\hline Component & Number & Query \\
\hline Patients (P) & $\# 1$ & $\begin{array}{l}\text { ((cardiac or cardiovascular or coronary) and risk) or ((cardiovascular or heart or atherosclerotic or coronary or } \\
\text { cerebrovascular) and disease*) or coronary artery or diabet* }\end{array}$ \\
\hline $\begin{array}{l}\text { Interventions (I) } \\
\text { and } \\
\text { comparators } \\
\text { (C) }\end{array}$ & \#2 & $\begin{array}{l}\text { (aspirin or acetylsalicylic acid) and (proton pump inhibitor* or omeprazole or esomeprazole or pantoprazole or } \\
\text { lansoprazole or dexlansoprazole or rabeprazole) }\end{array}$ \\
\hline \multirow[t]{4}{*}{ Outcomes (0) } & \#3 & $\begin{array}{l}\text { ((gastric or gastrointestinal or gastro duodenal or duodenal) and (symptom* or complication*)) or ulcer* or bleeding } \\
\text { or hemorrhage or haemorrhage or obstruction or } \\
\text { perforation or toxicity or injury or damage }\end{array}$ \\
\hline & $\# 4$ & $\begin{array}{l}\text { ((cardiac or cardiovascular or atherosclerotic) and event*) or heart attack or myocardial infarction or stroke or death } \\
\text { or mortality or survival rate }\end{array}$ \\
\hline & $\# 5$ & (aspirin or acetylsalicylic acid) and (adherence or compliance) \\
\hline & \#6 & $\# 3$ or \#4 or \#5 \\
\hline PICO & $\# 7$ & $\# 1$ and \#2 and \#6 \\
\hline
\end{tabular}




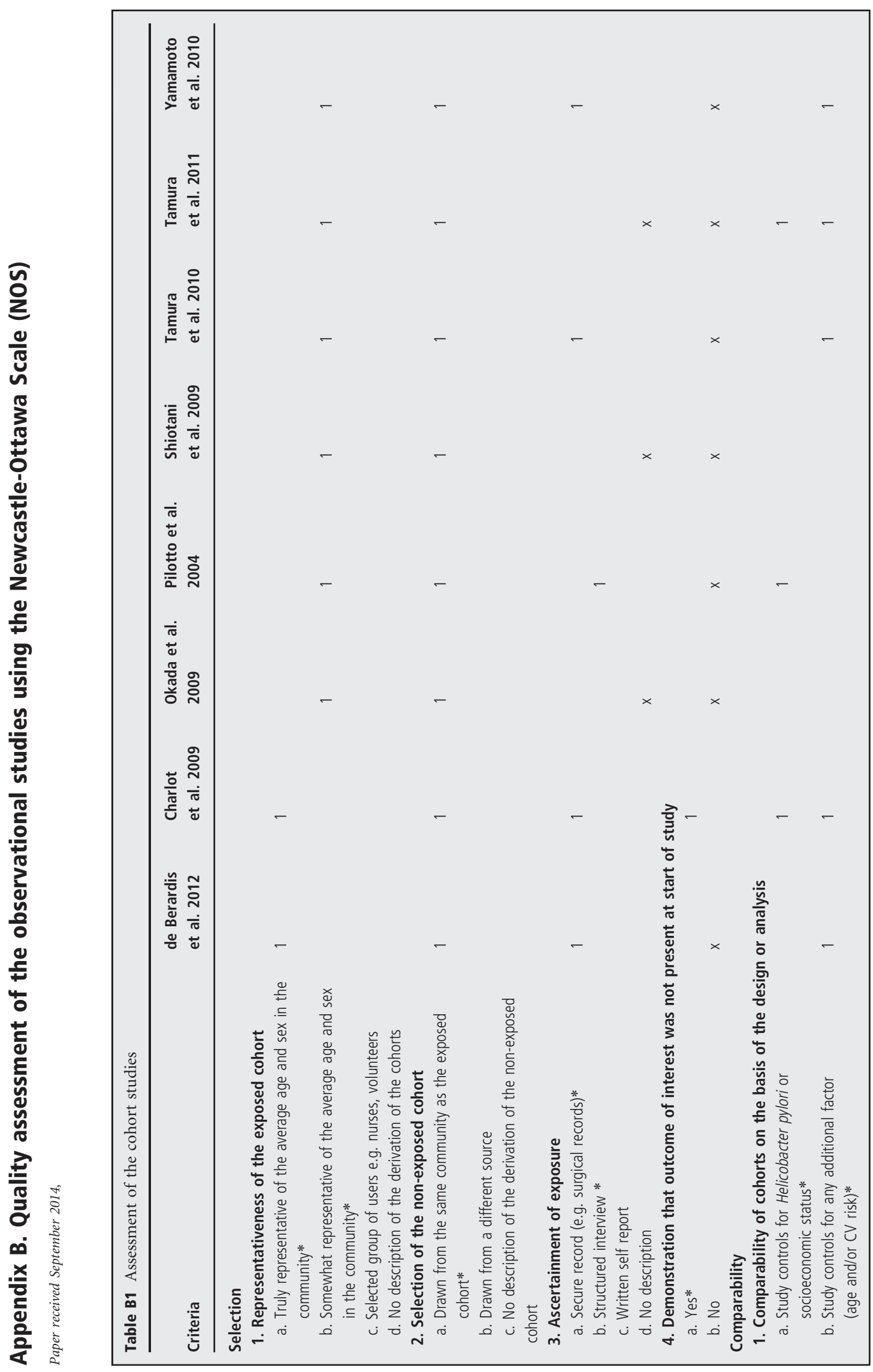




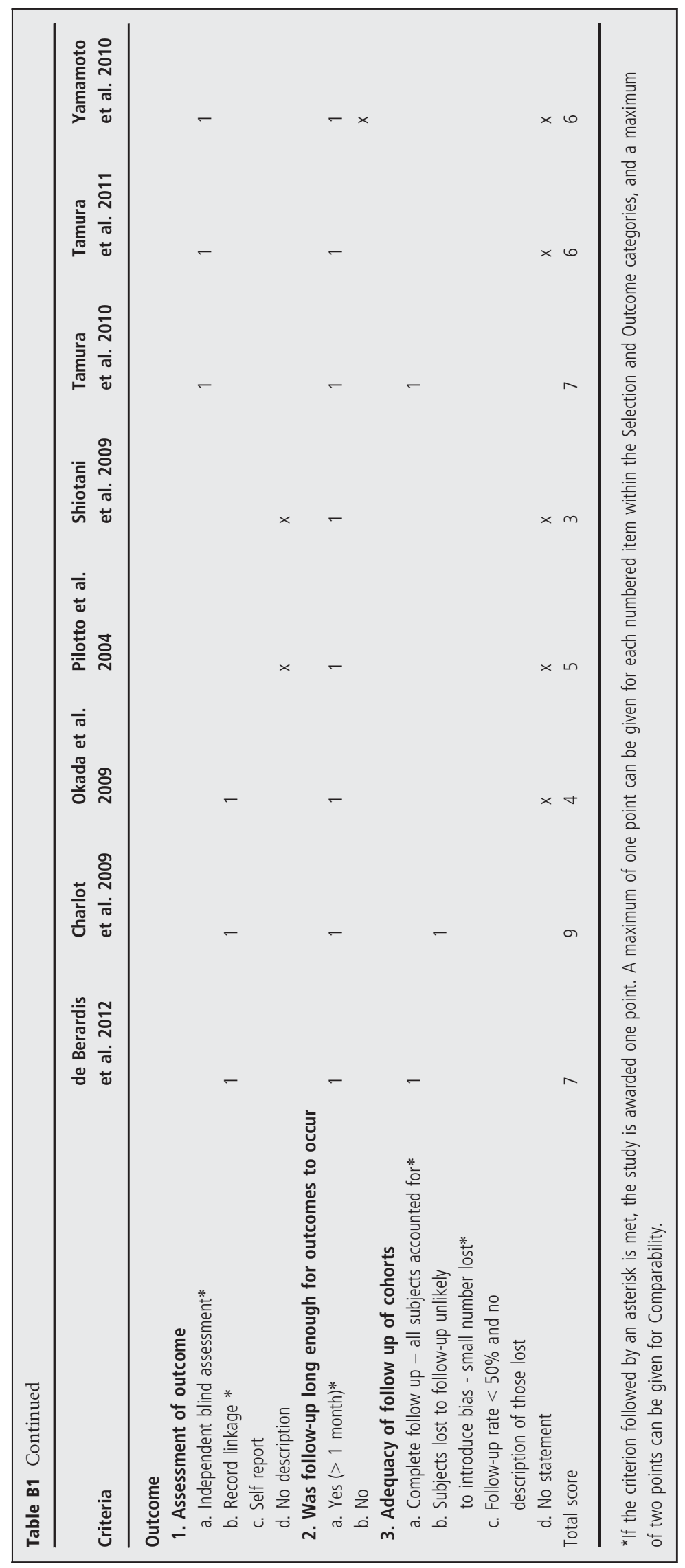


Table B2 Assessment of the case-control studies

Ibanez et al. 2006

Lanas et al. 2000

Lanas 2007

\section{Selection}

1. Is the case definition adequate?

a. Yes, with independent validation*

b. Yes, e.g. record linkage or based on self reports

c. No description

\section{Representativeness of the cases}

a. Consecutive or obviously representative series of cases*

b. potential for selection biases or not stated

\section{Selection of controls}

a. Community controls*

b. Hospital controls

c. No description

\section{Definition of Controls}

a. No history of disease (end-point)*

b. No description of source

\section{Comparability}

1. Comparability of cases and controls on the basis of the design or analysis

a. Study controls for Helicobacter pylori or socioeconomic status*

b. Study controls for any additional factors (age and/or CV risk)*

\section{Exposure}

\section{Ascertainment of exposure}

a. Secure record (e.g. surgical records)*

b. Structured interview where blind to case/control status*

c. Interview not blinded to case/control status

d. Written self report or medical record only

e. No description

\section{Same method of ascertainment for cases and controls}

a. Yes

$x$

b. No

\section{Non-response rate}
a. Same rate for both groups*
b. Non respondents described
c. Rate different and no designation

Total score

* If the criterion followed by an asterisk is met, the study is awarded one point. A maximum of one point can be given for each numbered item within the Selection and Exposure categories, and a maximum of two points can be given for Comparability. 


\section{University Library}

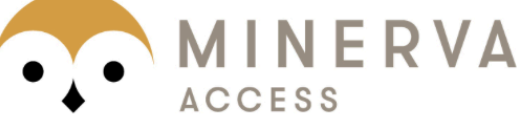

A gateway to Melbourne's research publications

Minerva Access is the Institutional Repository of The University of Melbourne

Author/s:

Tran-Duy, A;Vanmolkot, FH;Joore, MA;Hoes, AW;Stehouwer, CDA

Title:

Should patients prescribed long-term low-dose aspirin receive proton pump inhibitors? A systematic review and meta-analysis

Date:

2015-10-01

Citation:

Tran-Duy, A., Vanmolkot, F. H., Joore, M. A., Hoes, A. W. \& Stehouwer, C. D. A. (2015). Should patients prescribed long-term low-dose aspirin receive proton pump inhibitors? A systematic review and meta-analysis. INTERNATIONAL JOURNAL OF CLINICAL PRACTICE, 69 (10), pp.1088-1111. https://doi.org/10.1111/ijcp.12634.

Persistent Link:

http://hdl.handle.net/11343/123655 